\title{
Genetic Mechanisms Underlying Cortical Evolution in Mammals
}

\author{
Lucía Florencia Franchini* \\ Instituto de Investigaciones en Ingeniería Genética y Biología Molecular (INGEBI), Consejo Nacional de Investigaciones \\ Cientificas y Técnicas (CONICET), Buenos Aires, Argentina
}

OPEN ACCESS

Edited by:

Michael Piper,

The University of

Queensland, Australia

Reviewed by:

Wieland B. Huttner,

Max Planck Institute of Molecular Cell Biology and Genetics, Germany

Mercedes Paredes,

University of California, San Francisco,

United States

${ }^{*}$ Correspondence:

Lucía Florencia Franchini franchini@dna.uba.ar

Specialty section:

This article was submitted to

Stem Cell Research,

a section of the journa

Frontiers in Cell and Developmental

Biology

Received: 03 August 2020 Accepted: 08 January 2021

Published: 15 February 2021

Citation:

Franchini LF (2021) Genetic Mechanisms Underlying Cortical

Evolution in Mammals.

Front. Cell Dev. Biol. 9:591017.

doi: 10.3389/fcell.2021.591017
The remarkable sensory, motor, and cognitive abilities of mammals mainly depend on the neocortex. Thus, the emergence of the six-layered neocortex in reptilian ancestors of mammals constitutes a fundamental evolutionary landmark. The mammalian cortex is a columnar epithelium of densely packed cells organized in layers where neurons are generated mainly in the subventricular zone in successive waves throughout development. Newborn cells move away from their site of neurogenesis through radial or tangential migration to reach their specific destination closer to the pial surface of the same or different cortical area. Interestingly, the genetic programs underlying neocortical development diversified in different mammalian lineages. In this work, I will review several recent studies that characterized how distinct transcriptional programs relate to the development and functional organization of the neocortex across diverse mammalian lineages. In some primates such as the anthropoids, the neocortex became extremely large, especially in humans where it comprises around $80 \%$ of the brain. It has been hypothesized that the massive expansion of the cortical surface and elaboration of its connections in the human lineage, has enabled our unique cognitive capacities including abstract thinking, long-term planning, verbal language and elaborated tool making capabilities. I will also analyze the lineage-specific genetic changes that could have led to the modification of key neurodevelopmental events, including regulation of cell number, neuronal migration, and differentiation into specific phenotypes, in order to shed light on the evolutionary mechanisms underlying the diversity of mammalian brains including the human brain.

Keywords: brain, elephant, cetacea, primates, human, cortex, human accelerated region, synapsids

\section{INTRODUCTION AND ROAD MAP FOR THIS REVIEW}

In this review I propose a journey through the evolutionary history of the cortex in mammals. From the appearance of the six-layered neocortex in an ancestor of mammals to the evolution of the human brain. Although in this work, I compare the neocortex of mammals to homologous brain regions of other amniotes, an exhaustive comparison of the different brain plans in reptiles, birds and mammals and the different hypotheses that have been delineated to explain their evolutionary history are outside the scope of this review. For this matter excellent reviews and books are available (Northcutt and Kaas, 1995; Aboitiz et al., 2002; Striedter, 2005; Medina, 2007; Bruce, 2010; Montiel and Aboitiz, 2015; Montiel et al., 2016; Goffinet, 2017; Nomura and Hirata, 2017; Kaas, 2020). I mainly focus this review on the developmental pathways that were probably modified to render the mammalian neocortex. In addition, I analyze current knowledge about the evolution of the 
brain in mammalian lineages that are characterized by highly elaborated cognitive capacities such as elephants, primates and cetaceans. Finally, I concentrate on recent findings in humanspecific genetic modifications and their potential impact in the evolution of the human brain.

\section{THE MAMMALIAN BRAIN}

\section{Basic Plan}

Mammals are the most widespread group of vertebrates having conquered a large variety of ecological niches on land, water, and air. There are around 5,500 mammalian species today classified in 18 orders. Three subgroups of mammals are clearly distinguished among living mammals. Monotremata (Prototheria), is a group of egg-laying mammals that live in Australasia and represented today by only two species of echidna and a species of platypus (Figure 1). Marsupialia (Metatheria) are pouched mammals living today in the Americas and Australasia and classified in 260 species, the most representative of which are the kangaroos and the opossums. Placentalia (Eutheria) is the largest group, with around 4,300 species divided in 18 orders that have been clustered in four major branches: Xenarthra, encompassing anteaters, armadillos, and sloths; Afrotheria, a group including elephants and tenrecs, Laurasiatheria, with bats, cats, cows and whales; and Euarchontoglires, a group composed of rodents, primates, flying lemurs and rabbits (Figures 1, 3).

Beyond the very well-known characteristics that distinguish mammals from other vertebrates such as hair, breast-feeding, jaws, dentition, etc., the mammalian brain allows this successful group to sense the world in a unique way. In fact, Mammals have evolved a series of innovations regarding the way they can read sensory clues, including a highly developed sense of smell and the ability to better detect and discriminate airborne sounds. On the other hand it has been hypothesized that mammals at some point became nocturnal and as a consequence they lost their ability to see color (Walls, 1942; Land and Osorio, 2003). Thus, these changes in the sensory system have also impacted in the brain centers that process sensory information. Beyond the diversity and specialization of the mammalian brain in different lineages a basic organization of the mammalian brain is characterized by a well-developed forebrain that contains a six-layered neocortex located dorsally. In fact, at the beginning of development, shortly after its closure, the neural tube forms rostrally three primary vesicles namely prosencephalon (forebrain), mesencephalon (midbrain), and rhombencephalon (hindbrain). These primary vesicles later develop into five secondary brain vesicles: whereas mesencephalon stays undivided, the prosencephalon splits to render the telencephalon and diencephalon, and the rhombencephalon is subdivided into the metencephalon and myelencephalon. From the telencephalon are developed the cerebral cortex together with several subcortical structures, including the hippocampus, basal ganglia, limbic system and the olfactory bulbs. Whereas the cerebral cortex primarily derives from the dorsal part of the telencephalon, the ventral telencephalon is composed of the ganglionic eminences (GE) from where interneurons that express the inhibitory neurotransmitter GABA originate and later migrate to the developing cortex (Gelman and Marín, 2010; Faux et al., 2012).

The cerebral cortex can be subdivided either into: isocortex and allocortex based on histological criteria; homogenetic and heterogenetic based on layer development timelines; or neocortex, paleocortex and archicortex based on evolutionary criteria. The archicortex consists of the hippocampal formation, which is located ventromedially related to the neocortex. This part of the cortex is involved in learning and memory. The paleocortex consists of the olfactory bulbs, limbic structures (amygdala), piriform cortex and secondary olfactory cortex and it is located ventrolaterally in relation to the neocortex.

The isocortex or neocortex in mammals is located dorsally and comprises the phylogenetically youngest cortical areas and it is characterized by a six-layered structure that develops during fetal stages and maintains this lamination pattern in adulthood. The neocortex mainly deals with sensory information beyond olfactory input that is processed at the piriform cortex. The neocortex is organized in regions specialized for different functions: these areas include primary visual (V1), somatosensory (S1), and auditory areas (A1). In addition there are other areas in the neocortex such as motor areas, secondary somatosensory, visual and other areas that vary from lineage to lineage.

Information from fossils (endocasts) and extant mammals is used to describe the basic brain of early mammals and protomammals. The fossil evidence indicates that early mammals had little neocortex relative to brain size and that piriform cortex and other areas dedicated to olfaction were more developed. Thus, the olfactory bulbs were quite large since early mammals had a very well-developed sense of smell. Regarding other areas of the brain, it is very probable that ancestral mammals lacked a corpus callosum that connects both cerebral hemispheres since although this structure is present in all placental mammals it is not found in monotremes or marsupials (Aboitiz and Montiel, 2003; Mihrshahi, 2006; Kaas, 2013). On the other hand, in the basal ganglia, the striatum is present in all tetrapods and receives dopaminergic projections from the diencephalum and/or the tegmentum, thus we suppose that basal ganglia were present in ancestral mammals. Moreover, other structures such as the nucleus accumbens, pallidum (globus pallidus) were also present as in all tetrapods.

\section{The Emergence of the Mammalian Brain: Comparison to Other Tetrapods Brains}

What is different about the mammalian cortex compared to other tetrapods? In the reptiles the homologous forebrain region to the neocortex is the dorsal cortex but it possesses three layers of which only one possesses the neuronal bodies of pyramidal neurons and interneurons (Figure 2) (Aboitiz et al., 2002; Bruce, 2010; Molnár, 2011). In addition, reptiles and birds (sauropsids) possess a big structure in the telencephalon called the dorsal ventricular ridge (DVR) where many sensory inputs like visual, somatosensory and auditory, are processed and in this ways covers many of the functions of the mammalian neocortex (Figure 2). Several hypotheses have been proposed to explain the 


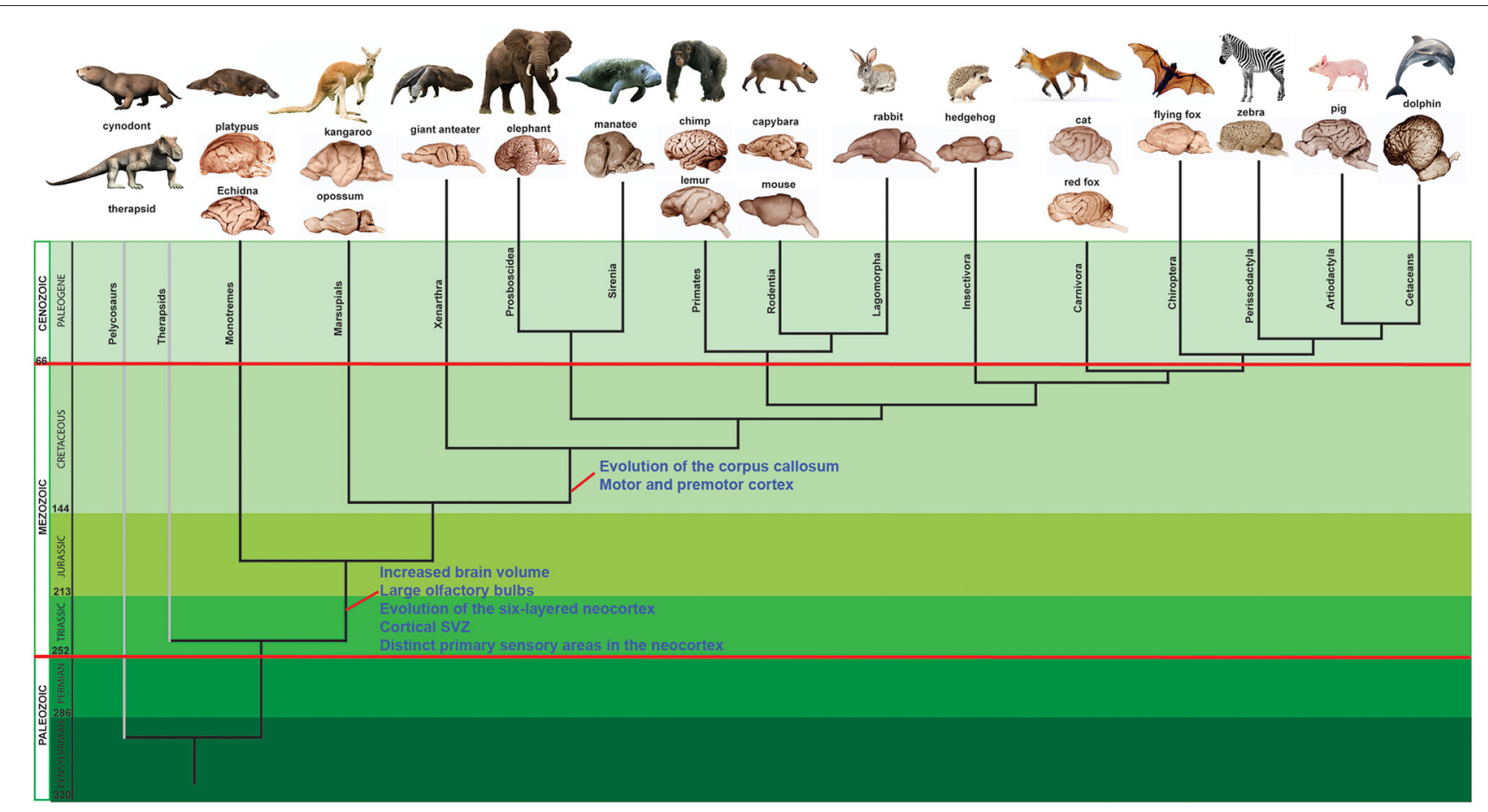

FIGURE 1 | Phylogenetic tree of mammalian evolution. The schematic phylogenetic tree has been based on phylogenetic trees built by Goffinet (2017) and Rowe (2017). Red lines mark the mass extinction events. In every lineage two examples of lissencephalic and gyrencephalic brains are shown. Extinct lineages show examples of species that have been described from fossils specimens. Drawings of Therapsid Proburnetia viatkensis Tatarinov species and Cynodont Kayentatherium wellesi Kermack species were performed by the artist Nobu Tamura (http://spinops.blogspot.com/) and reproduced with permission.

origin of the DVR of birds and reptiles but they are outside the reach of this review (see Striedter, 2005; Medina, 2007; Butler et al., 2011; Montiel et al., 2016; Puelles et al., 2017). In birds, although they have a large dorsal cortex, it is organized in nuclei and not in layers (Dugas-Ford et al., 2012). The dorsal cortex is called "Wulst" or hyperpallium (Reiner et al., 2004). There is almost no doubt that the Wulst is the homologous region to the dorsal cortex in reptiles and also to neocortex in mammals. However, it is small in the majority of birds compared to the mammalian neocortex and it has been suggested that it is the very big DVR in birds that plays many of the functions of the cortex in mammals (Figure 2). Since the Wulst process mainly visual and some somatosensorial inputs, it is more developed in those birds that have improved visual capacities (Striedter, 2005).

It is proposed that the stem amniotes from which mammals and present day reptiles and birds originated had a cerebral cortex in the telencephalon. In fact, a basic plan for the organization of this amniote cortex has been proposed (Puelles et al., 2016, 2017): this cortex is divided in a ventral part and three dorsal fields that includes medial, lateral, and dorsal components. Whereas, the medial part in sauropsids corresponds in mammals to the hippocampal formation, the lateral cortex coincides with the piriform cortex and the dorsal cortex corresponds to the neocortex (Puelles et al., 2016, 2017).

\section{How the Neocortex Is Made in Mammals?}

Before analyzing the genetic pathways that could underlie the evolution of the six-layered neocortex, I will summarize briefly how the cortex develops in mammals compared to sauropsids and birds. In mammals the cortex is composed approximately of $80 \%$ of excitatory glutamatergic neurons that are generated in situ through the proliferation and migration of progenitor cells. In addition, the cortex possesses GABAergic cortical interneurons that originate in the ganglionic eminences and that migrate to the cortex (Gelman and Marín, 2010; Faux et al., 2012). The neocortex develops through a process called neurogenesis from a single layer of neural progenitor cells (NPCs) that cover the lateral ventricles and that are present in early stages of brain development as neuroepithelial cells (NECs). This layer of progenitor cells that covers the lateral ventricles is known as ventricular zone (VZ) (Figure 2). In early stages of development NEC divide symmetrically to amplify the progenitor pool and then, at the onset of neurogenesis NECs acquire glia markers and are from this stage named as apical radial glia cells (aRG). Then, aRG can divide symmetrically or asymmetrically to give origin either to more aRG or to three other cell types: (i) basal radial glia (bRG), (ii) intermediate progenitors (IPs), or (iii) neurons (for a review of cell types see Florio and Huttner, 2014; Goffinet, 2017) (Figure 2).

IPs migrate into a new layer or proliferative zone called the Subventricular Zone (SVZ). In the SVZ, IPs divide symmetrically 
A

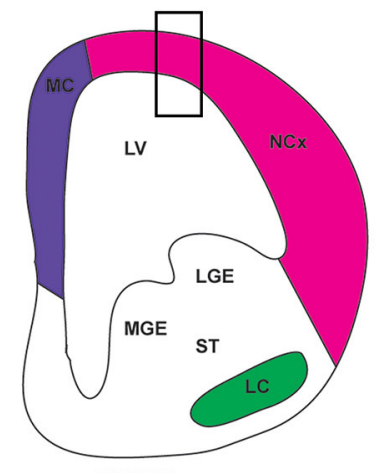

MAMMAL

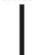

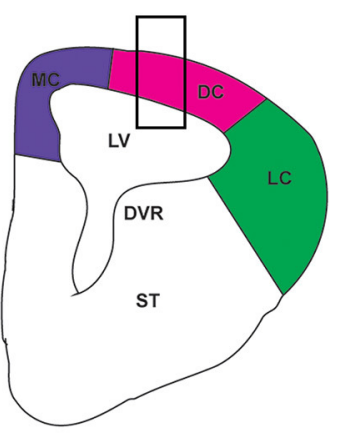

REPTILE

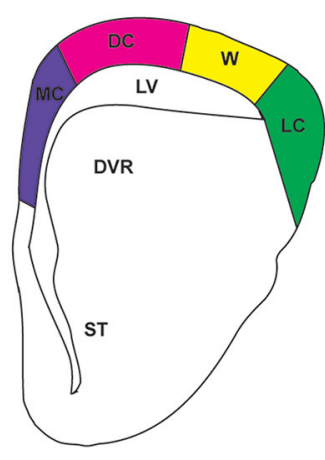

BIRD

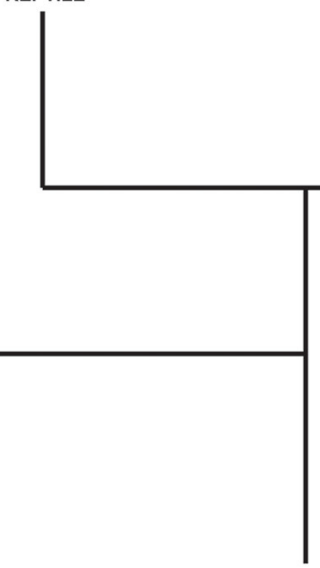

B
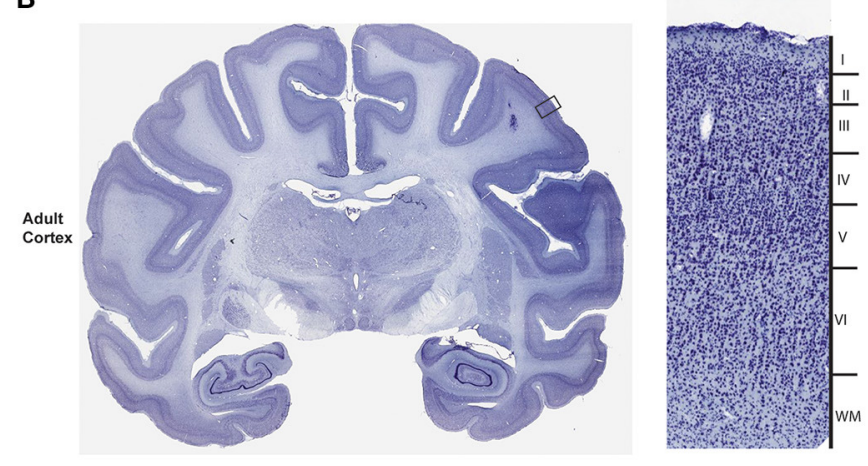

C

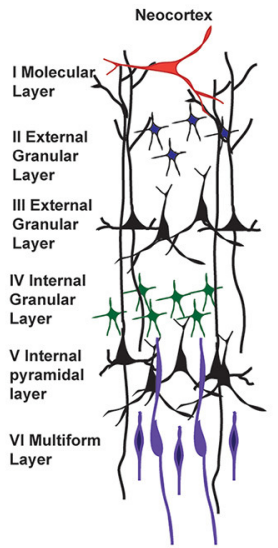

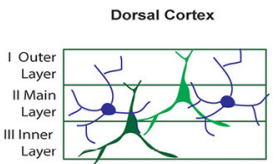

$\overbrace{}^{\text {Stellate }}$

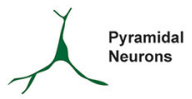

D
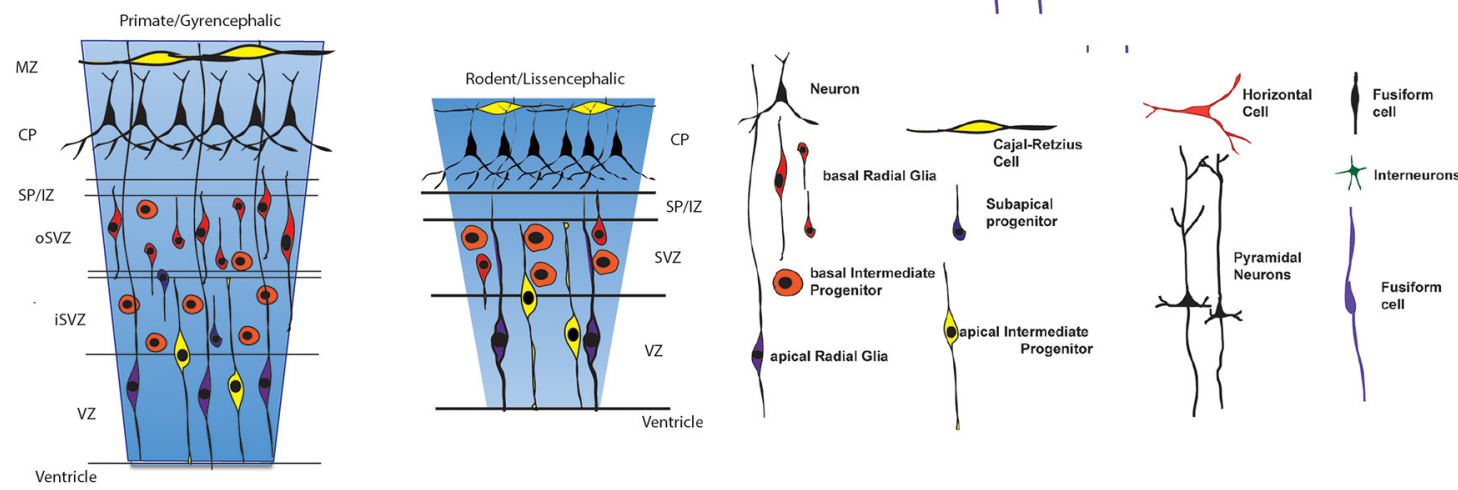

FIGURE 2 | Cortex across amniota. (A) Schematics of coronal sections at the forebrain in amniotes. On the left a drawing of the developing mammalian forebrain (based on the mouse) indicating the location of the neocortex (NCx), medial cortex (MC), lateral cortex (LC), and ventral telencephalic structures such as the lateral 
FIGURE 2 | and medial ganglionic eminences (LGE and MGE). In the middle and at the right schematics of the reptile and bird forebrains showing dorsal cortex (DC), medial cortex, lateral cortex, hyperpallium or Wulst (W), and subpallial structures as the dorsal ventricular ridge (DVR). The approximate location of the striatum is also indicated (ST). Colors indicate brain regions that are homologous among the different vertebrate lineages. Rectangles in mammal and reptile brains indicate approximate location of the layers schematic shown in (C). (B) A Nissl stained coronal section of the adult macaca rhesus forebrain is shown. The rectangle indicates the approximate location of the magnification shown at the right. Magnification shows layers of the neocortex. (C) Schematic of the six layers of the neocortex in the adult mammalian neocortex. Next, a drawing shows the three layers of the dorsal cortex in a reptile. (D) Representational drawings of the developing neocortex of a gyrencephalic primate and a lissencephalic rodent where the germinative zones and cellular types are indicated. Next to it, the different cellular types of the adult and the embryonic developing neocortex are indicated. Macaque rhesus (Macaca mulatta) brain slices are from BrainMaps: An Interactive Multiresolution Brain Atlas; http://brainmaps.org.

to generate more IPs, before differentiating into neurons. Early born neurons, in turn migrate through the intermediate zone (IZ) to form first the preplate and later the cortical plate (CP). Neurons are organized in the CP forming layers that are deposited during development in an inside to outside manner in which layers VI and V are formed first and then IV, III and II (for a review see Rakic, 2009). Layer I, that consist mainly of Cajal-Retzius neurons, is an exception to this insideoutside pattern since these cortical cells are born earlier (around mouse embryonic days 10-11.5) and migrate to form this layer (Germain et al., 2010). Layer I is called the molecular layer and contains very few neurons and together with layer II or external granular layer, and layer III which is the external pyramidal layer constitute the supragranular layers. The supragranular layers are the primary origin and termination of intracortical connections that permits communication between one portion of the cortex and other regions (Swenson, 2006). Layer IV or internal granular layer receives thalamocortical connections, mainly from specific thalamic nuclei. Layer $\mathrm{V}$ called the internal pyramidal layer and layer VI known as the multiform/fusiform layer constitute the infragranular layers, which function is to connect the cerebral cortex with subcortical regions. Each cortical layer contains different cell types, for instance the pyramidal cells are the main neuronal type within layers III and V (Figure 2).

In reptiles, like the turtles, it has been described that they possess a VZ where cell division occurs, but not SVZ has been found (Cheung et al., 2007). In diapsids, like the gecko, it has been shown that NE cells divide first symmetrically and then asymmetrically to generate neurons (Nomura et al., 2013a). In addition, neurogenesis in the cortex of turtles and lizards obeys an outside-to-inside gradient (Goffinet et al., 1986). In birds (particularly in the chick), it has been shown that they have a clearly distinguished SVZ where cell divisions occur at E8 and E10. This SVZ is present in pallial and subpallial structures like the DVR and basal ganglia but not in the dorsal cortex (Cheung et al., 2007).

\section{Evolution of the Six-Layered Neocortex in Mammals: When, How, and Where?}

To clearly establish when the first animal to be called mammal appeared on Earth depends on the definition of mammals. Mammals possess many distinctive characters but in the fossil record it is possible to find many animals that show a few but not all the characters that define mammals. The history of mammals is a very rich one and it starts very early on with the appearance of a lineage of reptiles that showed some of the distinctive mammalian characters. Here I will revise this story very briefly but excellent reviews and books on the matter can be found (Kemp, 2005; Kielan-Jaworowska et al., 2005; Rowe, 2017).

Early reptiles, now usually called "stem amniotes," originated from amphibians about 320 million years ago in the late Carboniferous (Colbert et al., 2001; Benton, 2015; Benton et al., 2015) and soon (around 305 mya) divided into two major clades, the sauropsid or diapsid clade and the synapsid clade. From the sauropsid clade originated modern reptiles and birds, while the synapsid clade, led to the appearance of early mammals $\sim 280$ mya (Figure 1). Stem synapsids are conformed by two groups: pelycosaurs and therapsids (Figure 1). It is known that after the Permian-Triassic mass extinction $80 \%$ of terrestrial vertebrates disappeared but some therapsids survived, particularly the dicynodonts and the cynodonts (Kemp, 2005) and from this last group it is documented that the stem mammals evolved $\sim 240$ mya (Figure 1).

Thus, during the first part of the Mesozoic era the first animals that are named mammals appeared. These early mammals (or Mammaliaformes) were very small, shrew-like insectivores that were mostly nocturnal or lived underground. As mentioned before, these habits did not require three color vision, which led to the loss of opsins at some point during the evolution of mammals whereas trichromatic color vision was conserved in diapsids (Rowe et al., 2011). From this group, the egg-laying prototherians splitted very early on around 200 mya, whereas the metatherians or marsupials diverged more recently, around 150 mya from the lineage leading to Eutherian or placental mammals (Figure 1). For many years, until around 66 mya, mammals were small animals like mice, rats or shrews and some of them a little larger like cats or dogs. When dinosaurs started to disappear, around 66 mya, mammals rapidly diverged and occupied a diversity of ecological niches (Figure 1). This adaptive radiation led to the appearance of a great diversity of mammals from all the mammalian orders, some of which inhabit the Earth today.

Regarding the appearance of the six layered neocortex it is known that all therian mammals, including placentals and marsupials possess a six layered neocortex. In fact, it has been shown that marsupials display an organized SVZ, determined by the presence of basal progenitor cells and a pattern of expression of genes that resembles the one found in eutherian mammals, implying that the SVZ emerged prior to the EutherianMetatherian divergence (Cheung et al., 2010).

In addition, it is now known that monotremes that splitted from the mammalian lineage very early on (around 200 mya; Figure 1) after the appearance of what are called stem mammals, 
have a six-layered neocortex (Krubitzer et al., 1995) and also the presence of a SVZ has been described (Ashwell and Hardman, 2012). This indicated that a six-layered neocortex was already present before the split between monotremes and therian mammalian lineages. Then, the question is: did synapsids have six-layered neocortex? Undoubtedly, to answer this question we have to analyze only fossil evidence. From reconstructions performed using brain endocasts and braincases it looks like there was no great development of the telencephalon (Kemp, $2005)$, thus the answer to the above question is probably not. However, very recently Laaß and Kaestner have reported what seems to be the earliest evidence of a structure analogous to the mammalian neocortex in the fossorial anomodont (Therapsid) Kawingasaurus fossilis from the late Permian of Tanzania (Laaß and Kaestner, 2017). This finding is striking because in all therapsids the telencephalon is apparently quite narrow and does not show any clear signs of enlargement (Hopson, 2001; KielanJaworowska et al., 2005; Kemp, 2009; Rowe et al., 2011). However, the authors of this finding concluded that the appearance of this neocortex-like structure is the result of convergent evolution (Laaß and Kaestner, 2017).

Thus, although this cannot be certainly established the appearance of a six-layered neocortex should have happened between the emergence of stem-mammals from therapsids (around $250 \mathrm{mya}$ ) and the evolution of monotremes (around 200 mya) (Figure 1).

In addition, regarding cynodonts there is a lot of discussion among specialist about the evolution of the brain in this group but the general agreement is that although it was very small compared to mammals there was some tendency to an increased size (Kemp and Parrington, 1979; Quiroga, 1980; Kemp, 2005; Kielan-Jaworowska et al., 2005).

Regarding Mammaliaformes, in addition to the general shape of the endocast that suggest an enlarged telecenplalon (Kemp and Parrington, 1979; Quiroga, 1980; Kermack and Kermack, 1984; Kielan-Jaworowska, 1986) and also the presence of a neocortex (Allman, 1999; Kielan-Jaworowska et al., 2005) there is also indirect evidence that the emergence of Mesozoic mammals marks the origin of the neocortex (Rowe, 2017). In fact, it has been suggested that the presence of a special kind of hair follicles called guard hairs involved in mechanoreception found in fossils from China (Ji et al., 2006) indicates the presence of somatosensory regions in the neocortex (Rowe, 2017).

Thus, it is apparent from the evidence analyzed so far that the expansion from a three- to a six-layered neocortex took place at some point in a Mammaliaformes in the lineage leading to the emergence of the common ancestor of all present day mammals. The emergence of a six-layered neocortex required the evolution of a developmental mechanism leading to increase neural production during embryonic neurogenesis. As mentioned before, in the mammalian embryonic cortex aRGs are the main type of progenitor cells, they form in the ventricular zone where they undergo mitosis to generate daughter cells that can take two different pathways: to leave the cell cycle and differentiate as neurons in a mechanisms known as direct neurogenesis or remain as progenitors an re-enter the cell cycle. In fact, aRGs give rise to two types of basal progenitors that migrate to build the subventricular zone (SVZ): bRGs and bIPs. These basal progenitors in turn divide to generate neurons in a two-step process known as indirect neurogenesis (Figure 2). Direct neurogenesis produces neurons in a fast way but also exhausts the progenitor pool rapidly. This is the mechanism that mainly produces neurons in the dorsal cortex of reptiles and birds. These diapsid derived vertebrates do not possess a SVZ in the homolog region of the neocortex, where indirect neurogenesis occurs in mammals (see above). Thus, it is possible that the evolution of this two-step mechanism of neurogenesis or indirect neurogenesis could be the key step in the evolution of the six-layered neocortex.

Moreover, this two-step neurogenesis mechanism that occurs in the SVZ could underlie the amplification of the number of neurons produced by increasing the pace and by lengthening the period of neurogenesis that is the raw material for the expansion of the cerebral cortex in diverse mammalian lineages.

\section{Cortical Folding in Mammals}

The size of the neocortex varies remarkably among mammalian species. The extension of the surface area of the neocortex, results in a pattern of folds that characterizes many mammals. For excellent comprehensive reviews on the matter see (Albert and Huttner, 2015; Striedter et al., 2015; Borrell, 2018; Kroenke and Bayly, 2018; Llinares-Benadero and Borrell, 2019). Cortical folding is the result of developmental mechanisms that lead to an extension increase of cortical layers which outcome is a pattern of gyri and sulci. Cortical folding has been described only in mammals. Species without cortical folding are called lissencephalic and species displaying folded brains are named gyrencephalic. Gyrification correlates with neocortical enlargement (Reillo and Borrell, 2012; Lewitus et al., 2013) and it is not the result of a particular evolutionary trend in some mammalian groups, as it is present in all mammalian orders (Figure 1). It has been postulated that folding appeared as an evolutionary solution to the problem of increasing cortical surface area without increasing the volume of the crania (Zilles et al., 2013). However, this hypothesis has been challenged by studies focusing on developmental mechanisms (Borrell, 2018). Cortical folding has been associated with the splitting of the SVZ and the appearance of the outer SVZ (oSVZ) in several gyrencephalic species (Reillo et al., 2011). In fact, the seminal finding by Smart et al. (2002) that in rhesus monkeys the SVZ was splited into two distinctive proliferative layers, i.e., oSVZ and inner SVZ (iSVZ) led to the identification of the oSVZ, as the principal source of cortical neurons in primates (Dehay et al., 2015). The oSVZ in rhesus monkeys and humans is populated by a particular kind of progenitor cell that is collectively known as basal Radial Glia (bRGCs). These progenitors were first described in the developing human neocortex (Fietz et al., 2010; Hansen et al., 2010) and then in other gyrencephalic mammals, such as ferret, cat and sheep (Reillo et al., 2011). In contrast, in the lissencephalic mouse, the SVZ is undifferentiated and a few bRGCs have been found (Wang et al., 2011). Thus, cortical folding has been also linked to a higher abundance of bRGCs in gyrencephalic vs. lissencephalic species (Wang et al., 2011; Pilz et al., 2013). Moreover, increasing the number of bRGCs in the 
mouse embryonic cortex through genetic manipulations leads to the appearance of folds (Stahl et al., 2013; Florio et al., 2015; Ju et al., 2016; Wang et al., 2016). Although, some lissencephalic mammals such as the marmoset and rats display a small oSVZ (Kelava et al., 2012; Martínez-Cerdeño et al., 2012). The presence of oSVZ-like structures in several placental mammals orders had led to propose that this structure appeared in an ancestor of placental mammals before the divergence of most groups and that was later lost in some species like mice (Dehay et al., 2015).

Regarding the genetic programs underlying cortical folding, several genes have been involved in different mechanisms and at different stages. Many of them were identified in people exhibiting cortical folding anomalies, such as polymicrogyria and lissencephaly. In fact, patients carrying mutations in genes such LIS1, doublecortin (DCX), and cyclin-dependent kinase 5 (CDK5) show lissencephaly (Pilz et al., 1998; Kerjan and Gleeson, 2007; Magen et al., 2015). Genetic manipulations in animal models such as the ferret that displays a gyrencephalic brain, have allowed to show that in fact CDK5 knockout in the ferret cerebral cortex in vivo impairs cortical folding (Shinmyo et al., 2017). Moreover, ferrets lacking DCX lack cortical folds (Kou et al., 2015). As mentioned before, genes affecting the generation and amplification of bRGCs are key factors in the formation of cortical folds. For instance, loss of function of the protein Trnp1 and activation of the SHH signaling pathways increased the number of bRGCs and led to the appearance of cortical folding in mice (Stahl et al., 2013; Wang et al., 2016). It has also been shown that extracellular matrix components such as HAPLN1, Lumican, and Collagen I induce folding of the cortical plate in human fetal neocortex explant systems suggesting that extracellular matrix components play a role in the folding of the human neocortex (Long et al., 2018).

On the other hand, it was early suggested that cortical folding is determined by hydraulic pressure from the cerebrospinal fluid and blood vessels acting on a limited cranial volume (Welker, 1990). Although these early theories were discarded due to the lack of experimental evidence, it has been suggested more recently that cortical folding results from internal or external biomechanical forces (Kroenke and Bayly, 2018). In fact, computational and mathematical models combined with experimental approaches have been developed in order to explain the biomechanical forces that govern folding. In order to simplify computational models the developing brain is represented before the emergence of sulci and gyri, as a structure consisting of two zones: the inner zone composed by the tissue between the cortical plate and the ventricle and the outer zone, conformed by the cortical plate (Kroenke and Bayly, 2018). Then, two main hypothesis have been proposed to establish if the mechanical forces inducing folding arise from the outer or the inner zone: (i) "buckling due to differential expansion" that proposes that the tangential expansion of the outer zone relative to the inner zone is the main force inducing folding (Xu G. et al., 2010; Bayly et al., 2014) and (ii) "axon tension" that suggests that such forces emerge from axons in the inner zone (Richman et al., 1975; Van Essen, 1997). Another theory has been recently developed to explain the expansion of supragranular layers in primates (Nowakowski et al., 2016). This theory, named
"Supragranular Cortex Expansion Hypothesis," proposes that primate cortical neurogenesis progresses in two stages. During early neurogenesis, basal fibers of ventricular radial glia contact the pial surface and newborn neurons migrate along ventricular as well as outer radial glia fibers. In late neurogenesis, newborn neurons reach the cortical plate only along outer radial glia fibers that do not contact the ventricular surface. In this second stage the scaffold formed by radial glia is broken and there is a discontinuous scaffold formed by two morphologically and molecularly distinct radial glia subtypes: ventral RG and outer RG. This model proposes that the tangential and radial expansion of the supragranular neuronal layers in primates is only dependent in neurogenic divisions of outer RG cells leading to a disproportionate expansion of supragranular cortex relative to infragranular cortex (Nowakowski et al., 2016).

Although these theories based on genetics or biomechanical forces into the determination of cortical folding appear to build upon contrasting ideas, a combination of early events determined by molecular genetic programs that set the cellular composition of the cortex and later events determined by the regional varying mechanical forces seem to better explain the appearance of gyri and sulci in the brain cortex of mammals.

Certainly, the impressive amount of knowledge that has accumulated in the last years related to mechanisms underlying cortical folding has shed light on the evolution of this salient characteristic unique to mammals. In fact, there is clear evidence that the most recent ancestor to all mammals already exhibited a gyrencephalic brain (O'Leary et al., 2013; Lewitus et al., 2014). Thus, it is possible to speculate that in the ancestor of all extant mammalian lineages there were already molecular mechanisms that make it possible to generate a gyrencephalic brain.

Definitely the availability of more comparative studies among vertebrates and new advances in technologies promise to render a better understanding of the evolution of this complex mammalian feature. Moreover, as it will be discussed below, several hominoid-specific genes have been recently linked to the regulation of cortical folding in humans.

\section{Interneurons Origin, Development, and Evolution}

As mentioned before, during development the neocortex is populated by two main groups of neurons: excitatory projection neurons and inhibitory interneurons, that are mainly generated outside the cortex. In fact, inhibitory interneurons that mainly express GABA are originated in the medial and caudal ganglionic eminences and in the preoptic area and then migrate first tangentially in two streams over long distances into the cerebral cortex and then radially inside the cortex in order to become integrated into the various cortical layers (Buchsbaum and Cappello, 2019). The tangential migration of interneurons is regulated by multiple factors and although a deep review of them is not within the reach of this review, I will briefly mention some of the key factors involved in this important process of neocortical development. Excellent recent reviews on the matter are available (Faux et al., 2012; Hu et al., 2017; Lim et al., 2018). It has been shown that connexin 43 and Sox6 play important 
roles in the switch between tangential migration and radial migration (Azim et al., 2009; Batista-Brito et al., 2009; Elias et al., 2010). Another important factor controlling the correct path of migrating interneurons is the CXCL12/CXCR signaling pathway that seem to play a dual role, first attracting interneurons to the neocortex and then guiding their tangential migration until the correct radial signal is received (Faux et al., 2012). Once in the cortex, radial migration and lamination seem to be influenced by cues provided by pyramidal cells. Thus, neuregulin 3 (Nrg3) expressed by pyramidal cells, facilitates the dispersion of cortical interneurons in the laminar dimension of the cortex (Bartolini et al., 2017). The correct lamination of interneurons in the $\mathrm{CP}$ is controlled by intrinsic and extrinsic factors. Among the extrinsic factors, reelin seems to also play a role in the layering of these neurons since abnormal lamination has been observed when reelin signaling is disrupted (Hevner et al., 2004; Hammond et al., 2006; Pla et al., 2006; Yabut et al., 2007). However, it is not clear if it is due to reelin signaling (Hammond et al., 2006) or to the location of pyramidal neurons (Pla et al., 2006). Among the intrinsic factors it has been suggested that the time of generation, the site of origin and also the cellintrinsic genetic programs that they display influence not only on the final destination of interneurons in the cortex but also on the type of inhibitory cell that they become. Regarding the site of origin it has been suggested that interneurons arising from a common progenitor preferentially form clusters in the cortex (Brown et al., 2011; Ciceri et al., 2013) but this view has been recently challenged (Mayer et al., 2015). On the other hand, using single-cells transcriptome analyses, Mi et al. (2018) showed that shortly after the interneurons become postmitotic in their site of origin, their diversity is already evident due to the distinctive transcriptional programs that they display, and this transcriptional signature underlies their final differentiation in the developing cortex. Tangential migration by inhibitory interneurons from the subpallium to the pallium is a process highly conserved among vertebrates. There is evidence that suggests that the migratory pathways of neocortical GABAergic interneurons are mainly conserved among mammals (Tanaka and Nakajima, 2012). However, the site of origin may differ among species, because interneurons appear to be generated within the neocortex in addition to the ganglionic eminences in cynomolgus monkeys and humans (Letinic et al., 2002; Petanjek et al., 2009; Hansen et al., 2010; Jakovcevski et al., 2011; Yu and Zecevic, 2011). However, we are still far from understanding lineage-specific differences among mammals and vertebrates that can illuminate our knowledge about the complex mechanisms underlying interneurons development and evolution.

\section{GENETICS CHANGES UNDERLYING THE EVOLUTION OF MAMMALS}

\section{Birth of Mammals From a Genetics Perspective}

I will review in the following sections the genetic changes that could have led to the appearance of the neocortex in mammals. However, beyond the comparative studies analyzing particular gene functions in mammals and other tetrapods it is important to note at this point that the study of genome-wide changes in the lineage leading to mammals that could underlie the emergence of mammals is still in its infancy.

In this regard, it has been found that in the lineage leading to Eutherian mammals 357 novel ancestral placental genes appeared de novo through different mechanisms including gene duplication and divergence (Dunwell et al., 2017). Of these, 41 novel genes are expressed in the brain suggesting that the emergence of new genes has contributed to the evolution of the mammalian brain. Focusing on particular groups of genes, Niimura and Nei (2005) found a striking expansion of a particular group of olfactory receptor genes in mammals suggesting that this type of genes contributed to particular characteristics of this group of vertebrates. Although duplication and divergence of existing genes are two widespread mechanisms for the appearance of new genes, the emergence of genes completely de novo has been shown to play an important role in the evolution of mammals. In fact, it has been found that several key mammalian genes have originated de novo from non-coding sequences (Luis Villanueva-Cañas et al., 2017).

Furthermore, another mechanism of de novo origin of functional sequences, involves transposable elements. In this regard, it has been demonstrated that some particular families of transposable elements have been the origin of gene regulatory sequences that control the expression of pre-existing genes in the mammalian lineage (Santangelo et al., 2007; Sasaki et al., 2008; Franchini et al., 2011). Alongside, comparative genomics analyses have allowed to detect not only coding but also non-coding regions that evolved a higher rate in the therian mammalian lineage (Holloway et al., 2016). Actually, 4,797 accelerated regions, principally non-coding have been identified and it has been proved that several of them behave as transcriptional enhancers that gained function in mammals compared to the orthologous region in nonmammalian vertebrates. Altogether, these data suggest that mammals underwent extensive remodeling of their genome that led to the acquisition of novel genes and novel expression patterns that probably underlie the evolution of morphological and functional novelties that characterize them. However, since no specific genes or regulatory regions have been identified so far related to the acquisition of the six-layered neocortex, more bioinformatics and functional studies will be necessary to identify which genes underlie the evolution of this mammalian novelty.

\section{Genetic Pathways Underlying Mammalian Brain Development and Evolution}

To start unraveling the history of the genetic pathways that could underlie the evolution of the mammalian neocortex we need first to understand some of the genetic mechanisms that are in place during neocortex development. Thus, I will present in this section evidence from comparative studies that can help us to understand how changes in genetic mechanisms could have determined the evolution of the six-layered mammalian neocortex. There are several genetic pathways that are responsible for the development of the neocortex in mammals (Table 1). These 
TABLE 1 | Signaling pathways involved in brain development and evolution.

\begin{tabular}{|c|c|c|c|}
\hline Pathway & Functions & Reported species & References \\
\hline Wnt/b-catenin & - Controls precursor population & Mouse & $\begin{array}{l}\text { Chenn and Walsh, 2002; Logan and Nusse, } \\
2004\end{array}$ \\
\hline Fibroblast growth factors & - Regulate neurogenesis in the developing cortex & Mouse, human, ferret & $\begin{array}{l}\text { Raballo et al., 2000; Korada et al., 2002; Storm } \\
\text { et al., 2006; Rash et al., 2013; Masuda et al., } \\
\text { 2015; Heng et al., 2017; Matsumoto et al., } \\
2017\end{array}$ \\
\hline $\begin{array}{l}\text { Bone morphogenetic } \\
\text { proteins }\end{array}$ & $\begin{array}{l}\text { - Induce patterning of the telencephalon } \\
\text { - Promotes RGCs differentiation }\end{array}$ & Mouse & Li et al., 1998; Bond et al., 2012 \\
\hline Sonic hedgehog & $\begin{array}{l}\text { - Control the number of bRGCs and IPCs } \\
\text { - Induce cortical folding }\end{array}$ & Mouse, human & $\begin{array}{l}\text { Fuccillo et al., 2004; Dorus et al., 2006; Xu Q. } \\
\text { et al., 2010; Baudoin et al., 2012; Wang et al., } \\
\text { 2016; Yabut et al., } 2020\end{array}$ \\
\hline Notch & $\begin{array}{l}\text { - Represses proneural genes (Mash1, Ngn2, and Math1) } \\
\text { - Maintains RGCs stemness }\end{array}$ & $\begin{array}{l}\text { Human, mouse, chicken, } \\
\text { gecko }\end{array}$ & Kageyama et al., 2008; Nomura et al., 2013a \\
\hline Robo-Slit & $\begin{array}{l}\text { - Generation and migration of cortical interneurons and pyramidal } \\
\text { neurons }\end{array}$ & Mouse, chicken, snake & $\begin{array}{l}\text { Andrews et al., 2006; Hernandez-Miranda } \\
\text { et al., 2011; Zheng et al., 2012; Gonda et al., } \\
\text { 2013; Yeh et al., } 2014\end{array}$ \\
\hline Reelin & $\begin{array}{l}\text { - Controls radial migration and laminar positioning of pyramidal } \\
\text { neurons in the cortical plate }\end{array}$ & $\begin{array}{l}\text { Human, mouse, turtles, } \\
\text { crocodiles, lizards and } \\
\text { birds }\end{array}$ & $\begin{array}{l}\text { D'Arcangelo, 2005; Cabrera-Socorro et al., } \\
\text { 2007; Nomura et al., 2008; Meyer, } 2010\end{array}$ \\
\hline $\begin{array}{l}\text { Transcription factors and } \\
\text { transcriptional regulation }\end{array}$ & $\begin{array}{l}\text { - Influence the differentiation of functional regions of the cortex } \\
\text { - Control proliferation, differentiation and migration of cells in } \\
\text { the cortex }\end{array}$ & Human, mouse & $\begin{array}{l}\text { Nord et al., 2015; Ypsilanti and Rubenstein, } \\
2016\end{array}$ \\
\hline
\end{tabular}

pathways participate in the three different processes that are key during cortex development: neurogenesis, neural migration, and maturation.

\section{Wnt/b-Catenin Signaling Pathway}

The canonical Wnt signaling pathway plays a key role during brain development (Harrison-Uy and Pleasure, 2012). Wnt proteins act on target cells through the binding to a receptor complex [Frizzled (Fz)/low density lipoprotein (LDL) receptorrelated protein (LRP)] that is located at the cell surface of apical progenitors in the developing cortex. Ligand binding induces stabilization of the cytoplasmic b-catenin, which levels are regularly kept low as a consequence of the degradation triggered by its phosphorylation mediated by GSK3b (Logan and Nusse, 2004). Thus, when a cell receives Wnt, this signals triggers the inhibition of the degradation pathway, and as a consequence $\beta$ catenin is stabilized and translocates into the nucleus to associate to TCF/LEF transcription factors, which trigger the transcription of downstream effectors (Logan and Nusse, 2004). It has been shown that transgenic mice expressing a stabilized form of betacatenin in neural precursors develop enlarged brains and display an increase in cerebral cortical surface area and the appearance of folds mirroring sulci and gyri (Chenn and Walsh, 2002). However, it has been lately argued that the folding observed in this mouse model do not represent authentic gyrencephaly that normally affects only the pial surface but not the ventricular surface, whereas the folding observed by Chenn and Walsh affected both, the pial and the ventricular surface (Borrell, 2018).

\section{Fibroblast Growth Factor Signaling}

Fibroblast growth factor (FGF) ligands constitute a family of peptides that act both intracellularly and through secretion into the extracellular space. There have been described 22 FGFs so far and at least 13 have been shown to be expressed in the CNS throughout development (Fgf1,2, 3,7,8, 9,10,13,15,16,17,18,22) in particular areas of the neuroepithelium (Agirman et al., 2017). FGF ligands bind to their receptor FGFRs that are located in the cell membrane. So far four receptors have been described and three of them, FGFR1, FGFR2, and FGFR3 are expressed in the developing brain. It is now known that FGF signaling is critical for the regulation of neurogenesis in the developing cortex. In fact, it has been shown that the deletion of the Fgf2 gene decreased the number of glutamatergic excitatory neurons resulting in a reduced anterior neocortex (Raballo et al., 2000; Korada et al., 2002). In addition, it has been shown that mice with impaired Fgf8 gene expression display reduced proliferation and increased levels of apoptotic cells in the developing telencephalon (Fukuchi-Shimogori and Grove, 2001; Garel et al., 2003; Storm et al., 2006). It has been suggested that FGF signaling is key to the expansion of the SVZ. In fact, it has been reported that increased FGF signaling expands the generation of IPs without affecting bRGCs and leads to gyri formation in the rostrolateral developing forebrain (Rash et al., 2013). In addition, it has been shown that Erk-FGF signaling is more important in human RGCs compared to mouse RGCs since increasing Erk-FGF signaling in mice leads to the generation of bRGCs population without inducing folding in the neocortex (Heng et al., 2017). On the other hand, it has been revealed that increasing FGFs signaling into the ferret cerebral cortex through in utero electroporation, leds to an increase in the number of undulating folds, suggesting that an excess of FGF signaling is sufficient to induce the appearance of additional cortical folds (Masuda et al., 2015). Moreover, suppression of FGF signaling completely through the use of a dominant negative form of one of 
the FGF receptors, impairs cortical folding in the ferret showing that FGF signaling is required for cortical folding (Matsumoto et al., 2017). In addition, blocking FGF signaling reduces the proliferation of oSVZ progenitors. This evidence indicates that FGF signaling is critical for cortical folding in gyrencephalic mammals and is a key upstream regulator of the production of oSVZ progenitors (Matsumoto et al., 2017).

\section{Bone Morphogenetic Proteins}

Bone morphogenetic proteins (BMPs) are constituents of the transforming growth factor $\beta$ (TGF- $\beta$ ) superfamily (Derynck and Zhang, 2003; Shi and Massagué, 2003; Miyazono et al., 2010). BMPs bind to heterotetrameric complexes that consist of pair type I/II receptors and co-receptors and activation of these complexes results in the phosphorylation of particular cytoplasmic SMAD proteins that translocate to the nucleus to initiate transcriptional activity (Bond et al., 2012). BMP2, 4, 5, 6 , and 7 are secreted by the cortical hem and interact with Wnts to induce the dorsomedial patterning of the telencephalon (Bond et al., 2012). BMP2 and BMP4 are the main participants of the BMP signaling in the developing cortex (Shakèd et al., 2008). Previous studies reported that BMP signaling promotes the neuronal differentiation of RGCs (Li et al., 1998). In addition, more recently it has been shown that the null mutation of the Foxg1 gene generates hypoplasia of the mouse telencephalon and loss of ventral telencephalic structures (Martynoga et al., 2005). In these mice it is observed that excess neurons are produced leading to the depletion of the progenitor pool and constraining the growth of the telencephalon. These effects are mediated by the regulation of FGF and BMP signaling pathways (Martynoga et al., 2005). Although the key role of this signaling pathway is noticeable, a lack of comparative studies among mammals and other non-mammalian vertebrates prevent us from driving conclusions about the importance of this pathway in the evolution of the mammalian neocortex.

\section{Sonic Hedgehog}

Sonic hedgehog (Shh) is a diffusible secreted protein that belongs to the hedgehog family composed by two other members: Indian hedgehog (Ihh), and Desert hedgehog (Dhh) (Echelard et al., 1993; Roelink et al., 1994). In the developing forebrain, Shh is mostly secreted from the ventral telencephalon into the cerebro-spinal fluid (Ericson et al., 1995). In addition, it is also produced by Cajal-Retzius cells in the marginal zone (MZ) of the cerebral cortex, by the choroid plexus and by the interneurons that migrated to the cortical plate (Komada et al., 2008; Huang et al., 2010). Shh mediates its action via a receptor complex composed of two transmembrane proteins: Patched (Ptch1) and Smoothened (Smo) (Corbit et al., 2005; Rohatgi et al., 2007). Smo is a G-coupled protein that activates a complex signaling pathways that includes the activation of the Gli family (Gli1, Gli2, and Gli3) of transcription factors (Sasaki et al., 1999) that in turn activated among others the transcription factor $\mathrm{Nkx} 2.1$ that is required for the proper specification of specific interneuron subtypes (Butt et al., 2008). Besides, ectopic activation of Shh signaling in neocortical progenitors increase expression of FGF15, leading to the activation of FGF and
MAPK signaling pathways and triggers the expression of ventral forebrain progenitors typical genes (Yabut et al., 2020). In the ventral telencephalon, Shh signaling plays a key function in the production of GABAergic interneurons, which later colonize the cortical plate by tangential migration (Fuccillo et al., 2004; Xu Q. et al., 2010; Baudoin et al., 2012). In contrast, a more limited Shh signaling has been described in the developing cortex where its function is still poorly understood. However, it has been recently shown that the constitutively activation of Shh signaling in mice increased the number of bRGCs and IPCs and induced folding in the lissencephalic mouse neocortex, whereas the loss of Shh signaling reduced the number of bRGs and IPCs and neocortical size (Wang et al., 2016). In addition, it has been found that SHH signaling was greatly active in the human fetal neocortex whereas in the mouse embryonic neocortex Shh signaling displayed a reduced activity. Moreover, blocking SHH signaling in human cerebral organoids decreased the number of bRGs. These findings led the authors to propose that the strong SHH signaling observed in the human fetal neocortex may have contributed to bRGC and IPs expansion leading to neocortical growth and folding (Wang et al., 2016).

It has been reported that the molecular evolution of the gene SHH is dramatically accelerated in primates relative to other mammals. Within primates, the acceleration is most noticeable in the lineage leading to humans (Dorus et al., 2006). These results suggest that $\mathrm{SHH}$ underwent molecular changes under positive selection in the lineage leading to humans and this is interesting considering that the loss of one functional copy of SHH in humans leads to serious neurological and craniofacial developmental problems (Nanni et al., 1999) whereas the loss of one copy of SHH in mice does not induce appreciable developmental abnormalities (Chiang et al., 1999).

\section{Notch Signaling}

Notch receptors are transmembrane proteins composed of an extracellular EGF-like domain that bind ligands and an intracellular domain that after a series of modifications translocates into the nucleus. In fact, ligand binding triggers enzymatic events that result in cleavage of the intracellular domain that carries nuclear localization signals that guide it into the nucleus (Stifani et al., 1992; Schroeter et al., 1998; Struhl and Adachi, 1998). There are five Notch receptors and five canonical ligands belonging to the Jagged (Jag1 and Jag2) or Delta-like (Dll1, Dll2, Dll4) families (Zhang et al., 2018). In the developing cortex, the Notch signaling pathway is critical in regulating cortical neurogenesis. RGCs express Notch1 and Notch3 receptors and the ligands are expressed by neighboring neurons or IPs. After the ligand binds the Notch receptor, it experiences two successive cleavages, the first one is driven by the disintegrin/metalloprotease ADAM10 and the second one is performed by the $\gamma$-secretase and results in the release of the extracellular domain and the Notch intracellular domain (NICD). Then, NICD translocates to the nucleus and binds to $\mathrm{CBF} 1$ or Rbpj co-factor to trigger the transcription of many genes, including the Hairy enhancer of split (Hes) genes. Hes are transcription factors of the basic-helix-loop-helix (bHLH) family that repress the expression of proneural genes such as 
such as Mash1, Ngn2, and Math1, and ensure that RGCs preserve stemness (long-lasting progenitor potential) (Kageyama et al., 2008).

Comparative studies using a reptile model species (gecko), chicken and mouse have shown that Notch signaling is activated at different stages and in a species-specific manner in the developing cortex (Nomura et al., 2013a). In fact, using a Notch responsive reporter vector the authors show that geckos exhibit higher Notch activity particularly at later embryonic stages compared to mouse and chicken (Nomura et al., 2013a). These results suggest that the spatio-temporal regulation of Notch signaling in neural stem/progenitor cells could constitute the molecular mechanism underlying the inter-species differences observed in pallial neurogenic rates. These findings led the authors to hypothesize that changes in the regulation of neural stem/progenitor cells, including Notch signaling activation mechanisms, arose independently in the ancestors of mammals and archosaurs (Nomura et al., 2013a). Then, additional changes in the proliferation of apical progenitors and the emergence of basal progenitors might have contributed to the expansion of neurogenesis that characterizes the cerebrum of birds and mammals (Nomura et al., 2013a). Of note, it is important to mention that the Notch pathway underwent also speciesspecific changes in the human lineage (see below) supporting this hypothesis that pinpoint to the Notch pathway as a key player in the evolution of the neocortex in different non-mammalian and mammalian lineages.

\section{Robo-Slit Signaling}

The Roundabout (Robo) family of receptors together with their ligands, the Slit proteins, are abundantly expressed in the developing forebrain and play critical roles in the generation and migration of cortical interneurons (Andrews et al., 2006; Hernandez-Miranda et al., 2011) and also pyramidal neurons (Yeh et al., 2014). It has also been shown that Robol and Robo 4 play a role in radial migration of pyramidal neurons (Zheng et al., 2012; Gonda et al., 2013).

It has been recently shown that Robo1/Robo2 signaling plays a differential role between direct and indirect neurogenesis in the olfactory bulb (OB) vs. neocortical areas in mice (Cárdenas et al., 2018). Whereas, grows at a faster rate than the neocortex and this fast neurogenesis is due to higher direct neurogenesis in the OB. Double mutants for Robo1/Robo2 displayed impaired grow and development in the $\mathrm{OB}$ as a consequence of deficit in neurogenesis. Moreover, Slit1/2 double mutants showed the same defects observed in Robo1/2 mutants indicating that these are the receptors involved in neurogenesis in the OB. In order to understand which other pathways could be interacting with Robo-Slit signaling to control direct and indirect neurogenesis balance authors tested the Notch ligand Dll1 because it is expressed in a differential manner in the $\mathrm{OB}$ and the neocortex, showing lower levels in $\mathrm{OB}$ and higher in the neocortex. The authors found that Dll1 levels in the $\mathrm{OB}$ are increased in Robo1/2 mutants suggesting that Dll1 expression in the OB is downstream of Robo-Slit signaling. However, CRISPR/Cas9mediated impairment of Dll1 expression did not affect direct neurogenesis. Only the combination of overexpression of active forms of Robo1/Robo2 and reduction of Dll1 expression led to increased direct neurogenesis in the neocortex. These authors show that in the chicken dorsal cortex a Robo1/2 signaling also plays a role in maintaining the balance between direct and indirect neurogenesis. In the African house snake they found that the only mode of division in the dorsal cortex is direct neurogenesis and that manipulation of Robo signaling and Dll1 levels led to reduced direct neurogenesis. These results led the authors to propose that an attenuation of Robo signaling in the neocortex during mammalian evolution led to the emergence of cortical basal progenitors and the SVZ and the blockade of direct neurogenesis. The authors also hypothesize that these changes combined allowed the expansion and complexification of the mammalian cerebral cortex (Cárdenas et al., 2018). Although the hypothesis is tempting the genetic mechanisms that led to a decrease in Robol/2 expression in the mammalian neocortex need to be uncovered.

\section{Reelin-Mediated Signaling Pathways}

A striking difference between mammalian and sauropsids is the development of Cajal-Retzius (CR) cells (Figure 2). These cells are a special kind of neuron that is generated in the VZ located in the limit between dorsal and ventral telencephalon and also in the cortical hem. CR cells are the most significant source of reelin, an extracellular matrix glycoprotein essential for cortical development. CR cells migrate from their places of origin to the Marginal Zone (MZ) and through the secretion of Reelin they control radial migration and laminar positioning of pyramidal neurons of the cortical plate (Meyer, 2010). It has been shown that a mice mutant for the expression of reelin (reeler mouse) (for a review on this mutant see D’Arcangelo, 2005) displays a disorganized pattern of migration of neurons that result in an inverse layering of the cortex (reviewed by Aboitiz et al., 2002). Sauropsids like turtles, crocodiles, lizards and birds display scarce Reelin expressing cells in the telencephalic marginal zone during cortex development (Bernier et al., 1999, 2000; Goffinet et al., 1999; Bar et al., 2000; Tissir et al., 2003). This reduced Reelin expression apparently results from the lack of CR cells originated from the cortical hem or ventral pallium (Bielle et al., 2005; Cabrera-Socorro et al., 2007). It has been shown that the increase of Reelin expressing cells in the avian dorsal cortex through experimental manipulation modifies the RGC fibers organization and the patterns of neuronal migration, suggesting that the increase of Reelin signaling was a key step in the evolution of the mammalian neocortex (Nomura et al., 2008, 2009).

\section{Transcription Factors and Transcriptional Regulation}

In addition to the signaling pathways mentioned above, it has been shown that a plethora of transcription factors play key roles into the regionalization of the cortex and then in the proliferation, differentiation and migration of cells. In fact, several transcription factors that are expressed in graded anteroposterior and ventral-dorsal patterns influence the differentiation of functional regions of the cortex. For instance loss of function studies have shown that CoupTF1, Emx2, Lef1, Lhx2, Pax6, and $S p 8$ control the correct patterning of the cortex (Ypsilanti and Rubenstein, 2016). In addition, several transcription factors 
such as Tbr1, Tbr2, Pax6, Emx1, Emx2, Fezf2, Ngn1, Ngn2, and Satb2, that control the differentiation of glutamatergic neurons have been described (Lai et al., 2013; Ypsilanti and Rubenstein, 2016). Several recent reviews have analyzed in-depth the role of transcription factors in the development of the mammalian cortex, thus here I will only mention some salient examples of key $\mathrm{TF}$ controlling cortical development. For instance, Tbr1 and Tbr2 are transcription factors of the T-box family that play a key role in the proliferation and differentiation of glutamatergic neurons. For instance, Tbr2 controls the expression of hundreds of direct target genes and in this way influences the proliferation and differentiation of IPs in the developing cortex (Hevner, 2019). Another key transcription factor is Pax6 that controls patterning, migration, differentiation and neurogenesis in the cortex. The role of this TF in the development of the neocortex has been extensively reviewed elsewhere (Ypsilanti and Rubenstein, 2016). Regarding the development of GABAergic interneurons, several key transcription factors such as Dlx2, Dlx2, and Nkx2.1 have been reported. These TFs regulate the expression of many important genes and are master controllers of subpallial generation of interneurons (Nord et al., 2015). Regarding the role of TFs in the evolution of the neocortex, a few studies have explored this matter. A study analyzing comparatively TF networks in primates concluded that these pathways have been modified in a lineage-specific manner in the prefrontal cortex, suggesting that this could be a more widespread mechanism of brain evolution (Berto and Nowick, 2018). Although our understanding of the role of TFs in cortical development and evolution is still incomplete, the emergence of RNA-seq and epigenetic analysis techniques combined with the use of mutant mouse pedigrees is allowing us to understand better the gene regulatory pathways that are altered when a particular TF is absent. These techniques are also being used in non-mammalian vertebrates to analyze cortical development. In this way, we will soon have a better picture of the gene regulatory networks controlling cortex development in mammals and how these networks evolved in vertebrates to render the evolution of the six-layered neocortex.

\section{MAMMALS, BRAINS DIVERSITY AND THE EXPLOSION OF BEHAVIORAL COMPLEXITY}

\section{The Diversity of Mammalian Brains}

Mammals display a high diversity of brains and in the same mammalian order is frequent to find lissencephalic and gyrencephalic species (Figure 1). One interesting question is: which differences in developmental mechanisms in the neocortex underlie the cortical expansion observed in some mammals? As mentioned before, comparative studies among some model mammalian species are helping us to understand which cellular and molecular changes observed in the SVZ are correlated with changes in neural number and neural complexity. In the section below, I analyze current knowledge about the brains of different mammalian lineages that display the largest expansion of the neocortex.

\section{Big Brained Mammals: Elephants, Cetaceans, and Primates}

There are three lineages among placental mammals that display greatly enlarged brains: proboscidea that group elephants, cetaceans that assemble dolphins and whales and primates that include prosimians, monkeys, great apes and humans (Figures 1, 3).

\section{Elephants}

Elephants carry the largest brains of all terrestrial animals, and display the greatest cerebral cortex (Hart and Hart, 2007). Although elephants are capable of high order brain functions such as long-term memory, they are less able than Hominids like the chimpanzee in mirror self recognition or tool use. It has been recently found that the African elephant (Loxodonta africana) brain, which is about three times larger than the human brain contains 257 billion neurons, three times more neurons than the human brain but, the majority of these neurons (97.5\%) are located in the cerebellum. On the other hand, the cerebral cortex which has twice the volume of the human cortex carry 5.6 billion neurons which represents one third of the neurons found in the human cerebral cortex (Herculano-Houzel et al., 2014).

\section{Cetaceans}

Cetaceans are a group of mammals that share a common ancestor with Artiodactyla and that conquered aquatic environments $\sim 60$ mya (Thewissen et al., 2001). Today members of this order inhabit oceans and rivers, they are mainly predators and are characterized by long living periods, a dedicated offspring care system and a complex social organization (Marino, 2007, book). In addition, this group is distinguished by big brains, behavioral complexity and salient cognitive capacities (Marino, 2007; Marino et al., 2007). The brains of cetaceans are very large in both absolute and relative size and possess encephalization quotients (EQ) that are second only to humans (Marino, 1998). Actually, the largest brain on earth belongs to the sperm whale which can reach up to 8,000 cubic centimeters. Some cetaceans evidence some of the most sophisticated cognitive abilities among all mammals and show impressive convergence in terms of cognition with primates, including humans. In fact, cetaceans display complex social behavior such as alliances (Connor, 2007) and cultural transmission of information including hunting techniques (Allen et al., 2013). In addition, they show elaborated communication systems that include complex vocalizations and mimicry (Ridgway et al., 2012; Sayigh, 2014). It has been suggested that in cetaceans, brain size predicts the magnitude of social and cultural behaviors observed in this group of aquatic mammals (Fox et al., 2017). The brains of modern cetaceans are different in several aspects to other mammalian brains and also to their mammalian ancestors. Their brains are characterized by a great expansion of the cerebral hemispheres and auditory structures, and reduction of olfactory areas (Marino et al., 2007). The neocortex of cetaceans is characterized by lacking layer IV, so in contrast to other mammals instead of having six well-defined layers, cetaceans possess five layers. This change has important implications for the distribution of afferent connections to the neocortex (Marino et al., 2007). In addition, it has been shown that the frontal lobe is reduced in cetacean brains in clear contrast 


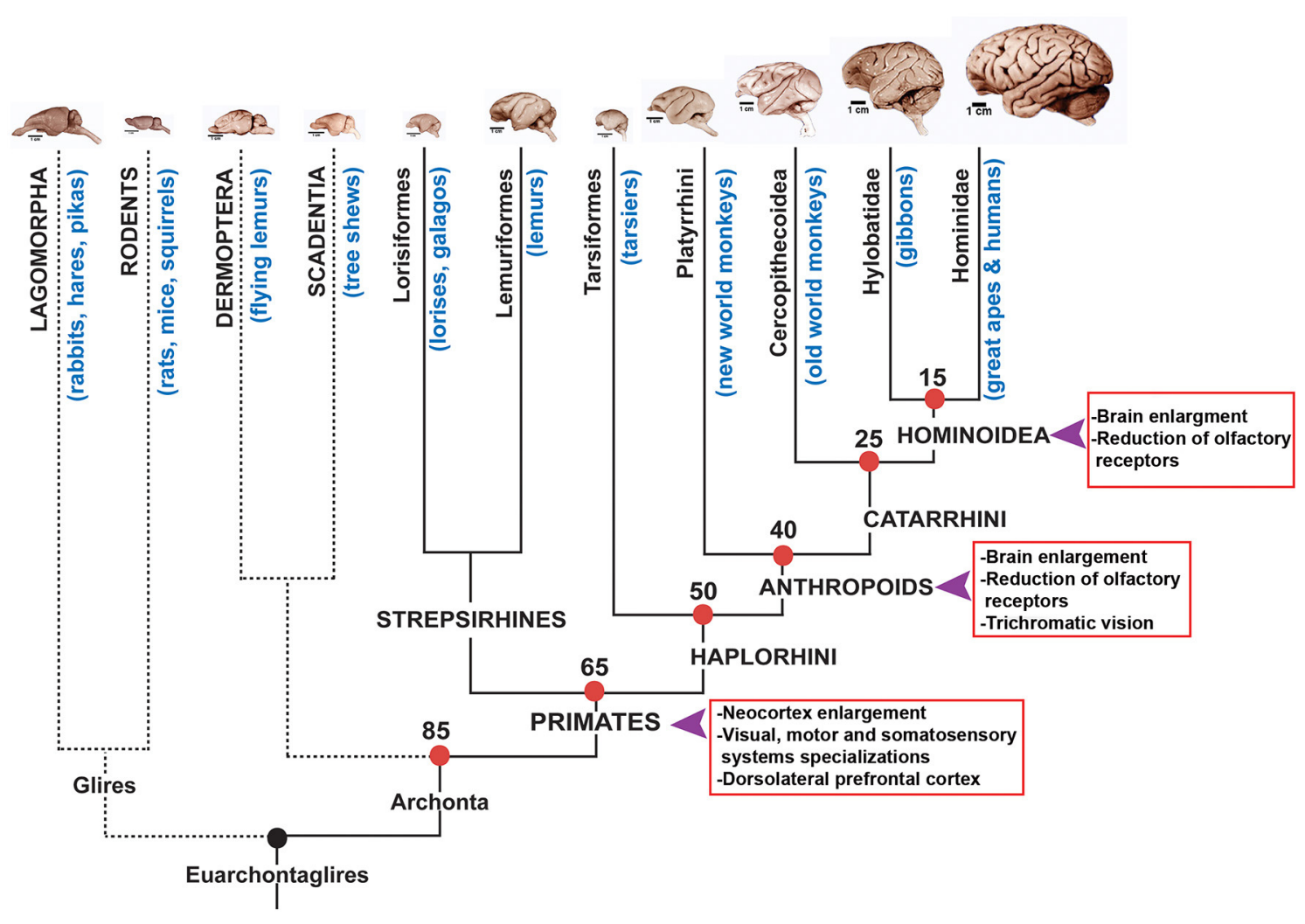

FIGURE 3 | Phylogenetic tree of primates and related mammalian orders. On the top row representative brains of the different groups that composed the Euarchontoglires clade are shown. Primate groups and approximate times of divergence are indicated on the tree. The arrows indicated moments in history where brain volume has increased in the Anthropoid lineage according to Goodman (1999). Brain pictures are approximately at scale and are from the Comparative Mammalian Brain Collection (http://neurosciencelibrary.org) from the University of Wisconsin and Michigan State Comparative Mammalian Brain Collections, as well as from those at the National Museum of Health and Medicine funded by the National Science Foundation, as well as by the National Institutes of Health.

to the enlargement of this region in primates (Morgane et al., 1980). It has been recently shown that cetaceans display in their cortices Von Economo neurons (Hof and Van Der Gucht, 2007; Butti et al., 2009). This type of neurons have been also described in humans, great apes (Allman et al., 2005, 2010) and elephants (Hakeem et al., 2009) and have been associated with certain aspects of higher cognitive abilities in humans such as social and emotional cognition, awareness, and intuition (Allman et al., 2005). It has been suggested that Von Economo have appeared convergently in phylogenetically unrelated groups of mammals like cetacean, hominids and elephants possibly under similar selective pressures that targeted specifically the evolution of cortical regions involved in complex cognitive and socialemotional capacities (Butti et al., 2009).

However, the lack of comparative gene expression studies in cetaceans and elephants prevents us from making any analyses about the gene and genetic pathways that could be involved in the evolution of the complex and marvelous elephant and cetaceans brains.

\section{Primates}

Primates emerged around 80-60 mya and then diversified in several groups that today are represented by more than 300 species (Figure 3). Primates have adapted to varied environments and ways of living and their brains show not only differences in size but also adaptations to different survival strategies. Primates display unique anatomical aspects compared to other mammals (Preuss, 2007; Kaas, 2013) and they also show differences in the way neurons and non-neuronal cells are packed in their brains (Herculano-Houzel et al., 2007). In addition, the neocortex in primates display much more functional areas subdivisions than non-primates. Thanks to the detailed analyses of prosimians (Strepsirrhine) it has been found that primates possess several cortical areas that are different compared to non-primates. One of the most distinctive characteristics of primates is their visual system, beyond the evolution of trichromatic vision that probably occurred in the Anthropoid lineage, it is also noticeable the frontal location of eyes which modified how information travels to the brain (Striedter, 2005). In the cortex, the primary visual area V1 is shared with all mammals but in primates it has specializations regarding connections and layering compared to non-primate mammals (Preuss, 2007). In addition, this primary visual cortex has two different processing modules and are dedicated to processing color information and orientation of the stimulus (Preuss et al., 1999; Kaas, 2012a). Besides, two other visual areas in the cortex (V2 and V3) also process visual 
information and show specializations in primates (Kaas, 2012b, 2013). Particularly it has been postulated that V3 is unique to primates and that a similar area that has been found in carnivores evolved independently (Kaas, 2012b). Comparisons between primate and non-primate brains indicate that the motor system is more complex and displays a higher number of premotor areas ( 9 or more) than non-primates that only have two to four (Wu et al., 2000). It has been shown that primates have a ventral premotor area that is involved in arm and mouth movements and that could be related to increased dexterity in primates (revised in Striedter, 2005). In addition, in primates it has been observed an increase in the number of somatosensory areas of the cortex that seem to be involved in touch sensitive fingertips and movement control (revised in Preuss, 2007).

As well, primates show a great development of an area located in the frontal lobe that has been related to higher order cognitive abilities such as decision making: the prefrontal cortex (Figure 4). Even though non-primate mammals do have a prefrontal cortex it seems to be composed of only two regions whereas primates display three regions: the orbital prefrontal region, anterior cingulate or medial region (these two are present in nonprimate mammals) and the dorsolateral or granular prefrontal cortex which seems to be unique to primates (Preuss, 1995, 2007; Striedter, 2005). Although there is some controversy about the dorsolateral prefrontal cortex being a primate innovation (Preuss, 2007) it is clear that this area is related to complex and flexible behaviors that are impaired when this area is damaged (Striedter, 2005).

Among primates, Apes displays a great enlargement of brain size and also a complex behavioral repertoire. Apes include the lesser apes with gibbons and siamangs and the great apes that include us, gorillas, chimpanzees, bonobos and orangutans. Compared to other primates, apes and humans (Hominoids) display larger brains, longer developmental periods, high energy requirements, lower reproductive rates and longer periods of parental care (Kaas, 2007, 2008, 2013).

Besides, it has been shown that the prefrontal cortex areas enlarged and became specialized during hominid evolution (Semendeferi et al., 2001). More recently it has been reported that human and great ape brain evolution is defined by the non-allometrically derived changes in cortical organization that include the extraordinary expansion of the prefrontal cortex (Smaers et al., 2017). It has been postulated that these changes in the prefrontal cortex underlies the increase in executive functions that characterize great apes and particularly humans and that are operated through this cortical region (Smaers et al., 2017).

\section{THE HUMAN BRAIN}

\section{Genetic Basis Underlying the Evolution of the Human Brain}

The human brain is a typical mammalian brain since it displays the six-layered neocortex with a well-developed SVZ. It has also the typical features of a primate brain such as a remarkably large neocortex including a large visual cortex and a lateral prefrontal cortex (Striedter, 2005; Preuss, 2007; Kaas, 2013).
In spite of these overall similarities, our brain has a number of features that make it unique. In fact, the development and anatomy of our brain differentiate in various critical aspects from those of other primates. For instance, the human brain has the largest number of neurons of any primate since it carries $\sim 86$ billion (Azevedo and Carvalho, 2009) compared with an estimated number of neurons in chimpanzee and gorilla brains of 28 and 33 billion neurons, respectively (Herculano-Houzel and Kaas, 2011). However, as described above, the human brain is not the largest on Earth, being eclipsed by the giant brains of elephants and cetaceans (Roth and Dicke, 2005; Hart and Hart, 2007; Marino, 2007). It has been calculated that $20.9 \%$ of all neurons in the human brain are located in the cortex, which is more than $10 \%$ greater than the proportion of cortical neurons in any other mammal (Herculano-Houzel, 2012). Although it is hotly debated whether our neocortex is particularly unique compared to chimpanzee (Barton and Venditti, 2013a,b; Smaers, 2013; Smaers et al., 2017), it is clear that the human cortex contains the most neurons (16/18 billion) and is proportionally the largest ( $84 \%$ of the entire brain mass) of any mammal (Herculano-Houzel, 2009, 2012; Herculano-Houzel et al., 2014).

Besides displaying the largest numbers of neurons the human brain is unique in several other aspects. In fact, post-mortem studies showed that our brain displays distinctive features in terms of cellular and histological organization of the cerebral cortex (Sherwood et al., 2008; Preuss, 2010; Miller et al., 2012). In addition, the use of diffusion-tensor imaging, a non-invasive brain imaging technique, allowed to study comparatively longrange interactions in the cortices of human, macaque and chimpanzee brains and revealed outstanding differences in cortical connections (Rilling et al., 2008).

However, in order to disentangle the evolution of humans' higher order cognitive abilities, such as abstract thinking, long term planning and an exceptional capacity to generate a complex language, we need first to address two challenging questions. The first is how to associate human cognition to particular neuroanatomical differences including brain size, number of neurons and a highly developed cortex. For instance, the neurobiological bases underlying our capacity to produce and elaborate language are not comprehensively understood, because surprisingly the essential areas controlling language in our brain are also present in chimpanzees (Cantalupo and Hopkins, 2001; Taglialatela et al., 2008). The second question is: how to link DNA changes to uniquely human neurobiology? (Figure 5). However, in the last two decades some progress has been made toward understanding the genetics underlying one of the most distinctive human cognitive traits: our spoken language (Vallender et al., 2008; Scharff and Petri, 2011; Preuss, 2012; Fisher, 2019). Nevertheless, we still know very little about how these genetic differences impact into molecular, cellular and anatomical mechanisms to shape the distinctive features of the human brain. Several attempts have been carried out to identify the genetic differences that could underlie the evolution of the human brain and many human-specific DNA sequences have been identified (Figure 5). After the sequencing of the human genome (Lander et al., 2001; International Human Genome Sequencing Consortium, 2004) as well as countless other mammalian 

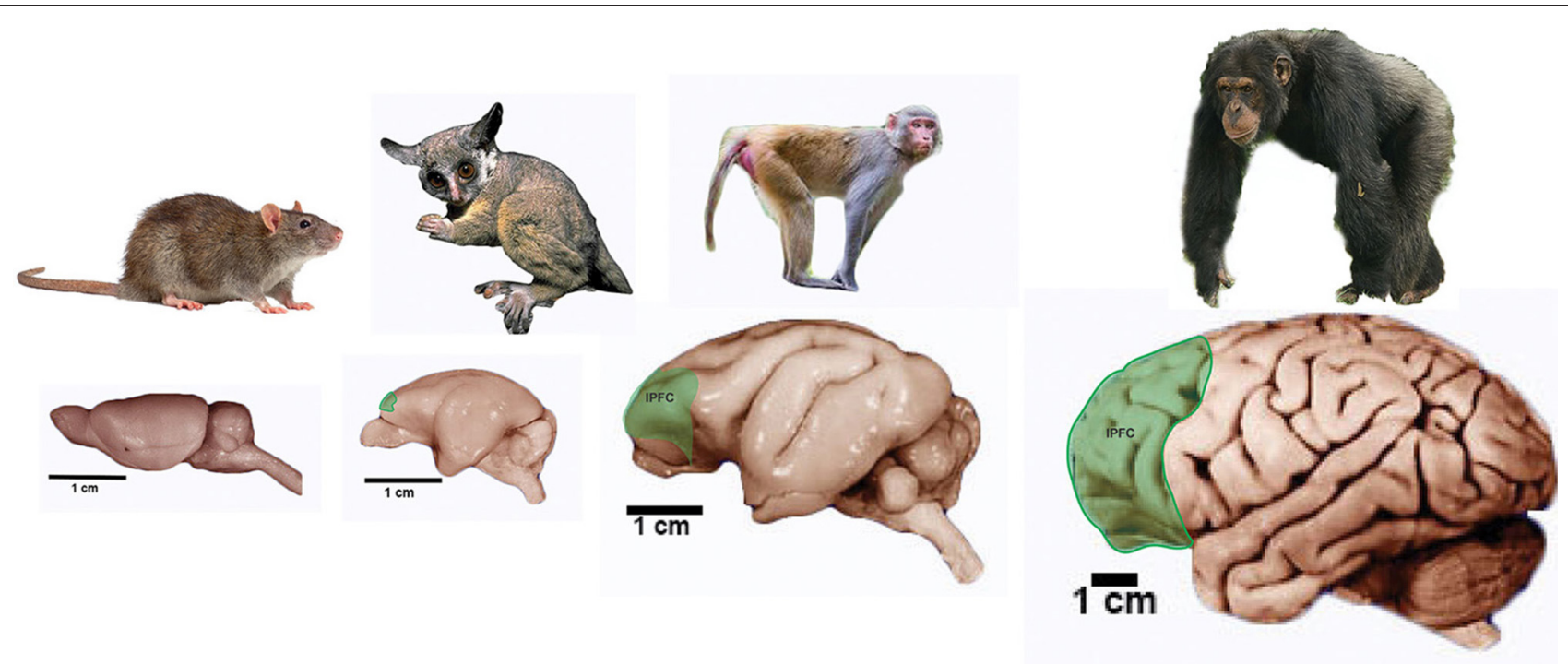

FIGURE 4 | Prefrontal cortex in primates. Pictures of representative primate groups and the rat show the approximate location of the lateral Prefrontal Cortex (IPFC). Brain pictures are approximately at scale and are from the Comparative Mammalian Brain Collection (http://neurosciencelibrary.org) from the from the University of Wisconsin and Michigan State Comparative Mammalian Brain Collections, as well as from those at the National Museum of Health and Medicine funded by the National Science Foundation, as well as by the National Institutes of Health.

genomes, including those of the macaque and the chimpanzee (Chimpanzee Sequencing Analysis Consortium, 2005; Rhesus Macaque Genome Sequencing Analysis Consortium et al., 2007), we have the availability of numerous genome-wide catalogs of human-specific genome changes that include genes that underwent positive selection in humans, genes displaying human-specific differences in splicing, chromosome segmental duplications that resulted in the appearance of new human genes and evolutionarily conserved non-coding sequences carrying human-specific mutations (reviewed in Sikela, 2006; Vallender et al., 2008; O’Bleness et al., 2012; Hubisz and Pollard, 2014; Bae et al., 2015; Silver, 2016; Franchini and Pollard, 2017; Sousa et al., 2017). The challenge that scientists of this century face is to connect human-specific genetic differences to unique human traits.

\section{Gene Duplication and Gene Loss}

The discovery of human-specific genomic variants began prior to genome sequencing. In fact, the use of chromatin-stained banding techniques allowed identification of the fusion of two ancestral hominid chromosomes that gave rise to human chromosome 2 and pericentric inversions on chromosomes 1 and 18. In addition, this technique uncovered the existence of humanspecific constitutive heterochromatin $\mathrm{C}$ bands on chromosomes 1, 9, 16, and Y (Yunis and Prakash, 1982). Large genomic deletions, duplications, and rearrangements are relatively rare, but due to their size, that could usually be thousands of base pairs, they frequently encompass many developmental loci and have a large impact on gene and phenotype evolution (Girirajan et al., 2011, 2013; Coe et al., 2014). Thanks to the use of techniques such as fluorescent in situ hybridization (FISH) and comparative genomic hybridization $(\mathrm{CGH})$ arrays it has been possible to identify more than 60 human-specific segmental duplications (Jauch et al., 1992; Goidts et al., 2006) and 152 genes displaying copy number variation (Fortna et al., 2004; Armengol et al., 2010). A significant amount of these structural variants have altered gene expression inducing phenotypical changes in humans. For instance, the pericentric inversion of chromosome 1, has been linked to neurogenetic diseases in humans and contains copy number variations of several developmental genes including HYDIN (Doggett et al., 2006), SLIT-ROBO Rho GTPase-activation protein (SRGAP2) (Dennis et al., 2012), and genes containing DUF1220 domain protein such as the neuroblastoma breakpoint family (NBPF) (Fortna et al., 2004; Dumas and Sikela, 2009). Thus, two rounds of human-specific duplication of the locus created four copies of the gene SRGAP2: SRGAP2A, SRGAP2B, SRGAP2C, and SRGAP2D (Dennis et al., 2012). In addition, it has been shown that SRGAP2C is expressed throughout and development and in the adult human brain (Charrier et al., 2012). It was also found that SRGAP2C dimerizes with the ancestral SARGAP2A and inhibits its function. It had been previously shown that the ancestral copy of SRGAP2 reduces the rate of neuronal migration and leads to a lesser amount of cells in the cortical plate (Guerrier et al., 2009). On the other hand the action of SRGAP2C inhibits this process and leads to an increased rate of migration (Charrier et al., 2012). In addition, SRGAP2C retards dendritic spines maturation in neurons. These results prompted the authors to suggest that the appearance of human-specific paralos of SRGAP2 contributed to the evolution of some features of the human brain (Charrier et al., 2012).

A distinct human-specific structural variant occurred at chromosome 15q13-q14 and resulted in the duplication of several genes, including $A R H G A P 11 B$, which is a partial copy of the gene 

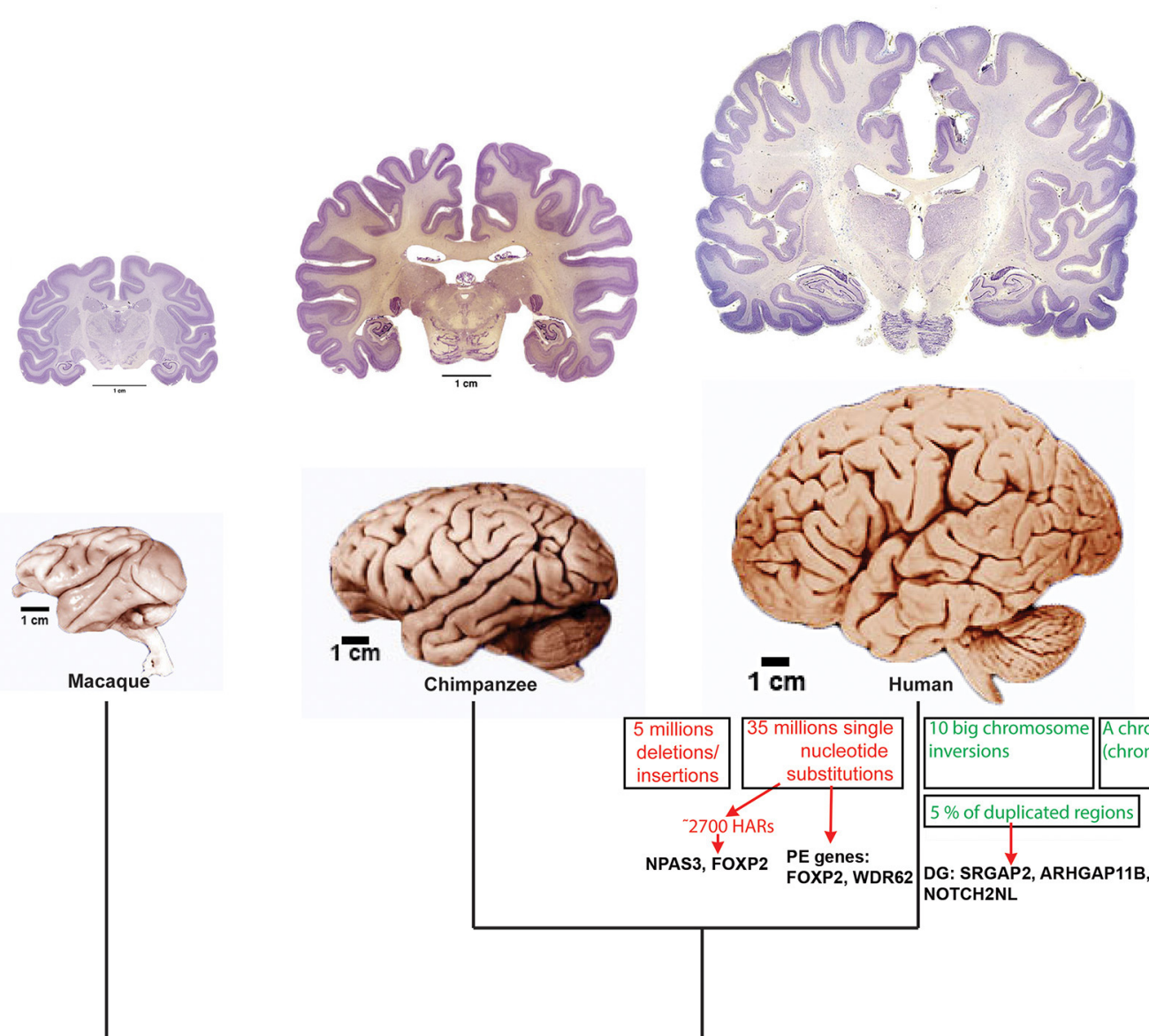

Chimpanzee

$1 \mathrm{~cm}$

Human

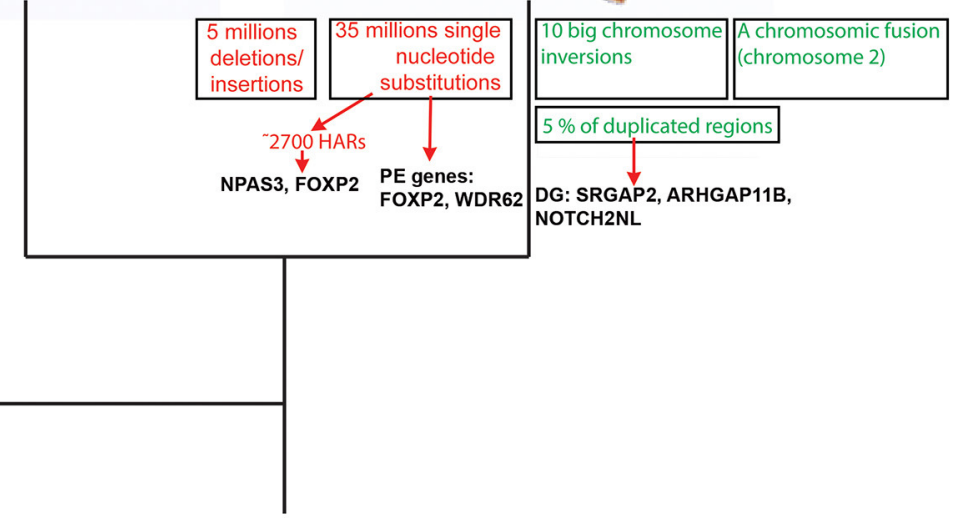

FIGURE 5 | Genetic changes underlying human nervous system evolution. A schematic phylogenetic tree shows the relationships among macaque, chimpanzee and human. Above that brain pictures show a detail of the size differences among these three primate species. Brains are shown at scale. On top of that, brain coronal sections at the forebrain level show anatomic differences among the species. It is appreciated the great development of the gyrification in the three species. Brain pictures are approximately at scale and are from the Comparative Mammalian Brain Collection (http://neurosciencelibrary.org) from the from the University of Wisconsin and Michigan State Comparative Mammalian Brain Collections, as well as from those at the National Museum of Health and Medicine funded by the National Science Foundation, as well as by the National Institutes of Health. On the lineage leading to humans some salient genetic changes that have been uncovered in the last years are indicated. PE, positively selected genes; DG, duplicated genes.

ARHGAP11A (Antonacci et al., 2014). ARHGAP11B appeared on the human evolutionary lineage after the divergence from the chimpanzee. In addition, the duplication of ARHGAP11B predates the split of our lineage with those of archaic humans since this gene is also found in Neanderthals and Denisovans. ARHGAP11B was identified as one of the exclusively expressed genes in human basal and apical radial glia compared to neurons in a transcriptomic analysis of the fetal human neocortex (Florio et al., 2015). To explore the function of ARHGAP11B in corticogenesis, Florio et al. expressed ARHGAP11B in mouse neocortex by in utero electroporation on embryonic day 13.5 (E13.5) (Florio et al., 2015). This led to an increase in basal but not apical mitoses and the expansion of Tbr2-expressing basal progenitors at E14.5. In turn, this increase in basal progenitors led to thickening of the SVZ. On the other hand, overexpression of ARHGAP11A did not increase basal progenitors. Furthermore, in half of the cases analyzed, ARHGAP11B expression induced at E13.5 resulted in neocortex folding at E18.5, in the otherwise smooth mouse neocortex. These mice showed an increase of cortical plate area in the gyrus-like structures compared with the contralateral smooth neocortex that displayed normal cortical lamination (Florio et al., 2015). In addition, it has been shown that ARHGAP11B displays a truncated GAP domain which is responsible for RhoGAP activity in ARHGAP11A (Florio et al., 2015). In fact, a single $C \rightarrow G$ base change in exon 5 in the ARHGAP11B gene generated a novel GU-purine splice donor site that induces the deletion of 55 nucleotides through mRNA splicing leading to the GAP domain truncation and addition 
of a human-specific carboxy-terminal amino acid sequence (Florio et al., 2016) which is unique to ARHGAP11B since it has not been yet found in any other protein described in the animal kingdom (Florio et al., 2015). It has been hypothesized that this novel domain has a key role in basal progenitors amplification induced by ARHGAP11B (Florio et al., 2016). Regarding the function of ARHGAP11B, it has been recently shown that this protein is localized in the mitochondria in contrast to ARHGAP11A which is found in the nucleus (Namba et al., 2020). In the mitochondria, this protein interacts with the adenine nucleotide translocase (ANT) and inhibits the mitochondrial permeability transition pore (mPTP), apparently leading to an increase in calcium concentration as well as an increase in glutamine-dependent mitochondrial respiration (Namba et al., 2020). This mitochondrial metabolic pathway is key for the increase in basal progenitors mitotic levels mediated by ARHGAP11B (Namba et al., 2020).

In order to study ARHGAP11B in gyrencephalic mammals, this gene was also introduced into ferret embryos, ferrets are gyrencephalic mammals that display an expanded neocortex and constitute more suitable models to study brain evolution and development in gyrencephalic brains (Kalebic et al., 2018). This manipulation increased proliferative basal radial glia number and resulted in extension of the neurogenic period leading to increased neuron density in the upper cortical layers (Kalebic et al., 2018). More recently, the generation of genetically modified common marmosets carrying ARHGAP11B under control of the human promoter of this gene that directs its expression to the developing neocortex increased the number of basal RGCs in the oSVZ of this lissencephalic primate leading to increased numbers of upper-layer neurons and induced an enlargement of the neocortex that resulted in cortical folding (Heide et al., 2020).

In addition, the recent description of NOTCH2 humanspecific paralogs suggest that progenitor proliferation and neuronal differentiation pathways have been modified in the human lineage. Two recent works found independently that the gene chromosome region where the gene $\mathrm{NOTCH} 2$ is located in the human genome (1q21.1) underwent a segmental duplication and as a result three human-specific paralogs appeared, NOTCH2NLA, NOTCH2NLB, NOTCH2NLC and NOTCH2NLR (Fiddes et al., 2018; Suzuki et al., 2018). It was previously shown that $N O T C H 2 N L$ is differentially expressed in neural stem and progenitor cells of fetal human neocortex and when this gene is expressed through electroporation in mouse embryos it promotes an increase in basal progenitors cell cycling (Florio et al., 2018). Furthermore, it has been shown that NOTCH2NL expression in mouse and human cortical organoids downregulates neuronal differentiation genes reducing differentiation of neural progenitors and increasing the final number of neurons (Fiddes et al., 2018). In addition, it was found that the presence of NOTCH2NL can block the expression of the Notch receptor DLL1, reducing neuronal differentiation (Suzuki et al., 2018). Altogether, these findings suggest that gene duplications have probably played an important role in the evolution of human-specific developmental mechanisms underlying cortical evolution. Altogether these studies support the adaptive role of duplications in human evolution (Iskow et al.,
2012), since both non-coding (Kostka et al., 2010) and coding (Hahn et al., 2007; Han et al., 2009) sequences in duplicated loci show signatures of positive selection.

Besides large duplications, human-specific duplications and deletions of DNA shorter than one kilobase are widespread and encompass approximately $3.5 \%$ of the human genome (Britten, 2002; Chimpanzee Sequencing Analysis Consortium, 2005; Varki and Altheide, 2005). These rearrangements contribute more base pairs than do individual DNA substitutions to humanchimp differences, but fewer than larger chromosomal variants. It has been shown that indels can have critical functional effects, by modifying or completely deleting conserved developmental enhancers and rendering altered human phenotypes. For instance, a polymorphic 13 base pair insertion in a sonic hedgehog ZRS limb enhancer induced preaxial polydactyly and the appearance of triphalangeal thumbs (Laurell et al., 2012). A genome-wide analysis found 510 highly conserved sequences that were lost in the human lineage. Most of these lost sequences were non-coding, and included a sensory vibrissae and penile spine enhancer for the androgen receptor gene and a transcriptional enhancer active in the SVZ of the developing cortex located near the tumor suppressor gene GADD45G (McLean et al., 2011).

\section{Point Changes in Coding and Non-coding Sequences}

The human and chimpanzee genomes accumulated since the split of these two lineages more than 30 million single nucleotide substitutions corresponding to the $1.2 \%$ of the human genome. Approximately half of these substitutions arose on the human lineage and the majority of them correspond to non-coding DNA (Chimpanzee Sequencing Analysis Consortium, 2005).

\section{Coding Changes}

According to the evolutionary theory most substitutions are nearly neutral and therefore are unlikely to have contributed to the emergence of uniquely human traits. In order to identify the genetic bases underlying functional differences in humans, research focused initially on the identification of nonsynonymous changes occurred in individual protein coding sequences that may lead to the appearance of novel protein functions or the origin of human-specific gene loss of function or pseudogenes. Comparison of nonsynonymous to synonymous substitution rates allows us to identify genes evolving under positive selection. Several studies focused on studying the evolution of genes in the human lineage identified brain expressed genes evolved that faster in humans (Dorus et al., 2004; Yu et al., 2006). However, the first comparative studies of humans and chimpanzees genomes also focused on protein-coding differences and found that positive selection in humans impacted mostly on genes involved in immunity, sensory perception, and reproduction but did not find a particular evolutionary trend in brain expressed genes in the human lineage (Clark et al., 2003; Bustamante et al., 2005; Nielsen et al., 2005). Other studies used population genetic data (Racimo et al., 2014) to identify genes that underwent positive selection after modern humans split from Neanderthals and Denisovans (Meyer et al., 2012; Prüfer et al., 2014). It has been hypothesized that several developmental genes that acquired human-specific coding changes could be 
responsible for the emergence of human-specific phenotypic traits (reviewed in Sikela, 2006; O'Bleness et al., 2012). These genes include the forkhead transcription factor FOXP2, which is associated with speech and language (Lai et al., 2001) and displays two human-specific amino acid substitutions that may have undergone positive selection (Enard et al., 2002; Zhang et al., 2002) although this consideration has been lately disputed (Ptak et al., 2009). In fact, more recent studies using human population data indicate that the pattern of variation in the FOXP2 locus does not suggest a recent selective sweep affecting the acquired amino acids (Atkinson et al., 2018). To investigate the function of these two human-specific amino acids genetically modified mice carrying the two human-specific amino acids in the FOXP2 were generated. These FOXP2 humanized mice showed differences in cortico-basal ganglia circuits including dopamine levels, synaptic plasticity and dendrite morphology (Enard et al., 2009). The engineered mice also showed differences in ultrasonic vocalizations compared to wild type (Enard et al., 2009) but these differences do not persist in the adults (Hammerschmidt et al., 2015).

Another interesting example is WDR62, a gene that encodes a centrosome-associated protein expressed in neuronal precursors and in postmitotic neurons in the developing brain and whose absence cause microcephaly with simplified gyri and abnormal cortical architecture (Nicholas et al., 2010; Yu et al., 2010). WDR62 shows accelerated evolution in the human terminal branch displaying six hominin-specific amino acids (Pervaiz and Abbasi, 2016). Although the functional consequences of these changes are yet to be understood, it is likely that the WDR62 hominin-specific amino acids modified its function (Pervaiz and Abbasi, 2016).

\section{Non-coding Evolution}

At the time that more vertebrate genomes were sequenced, it became possible to implement models of DNA evolution to screen the entire human genome in the search for sequences that changed significantly (more than expected by chance) since divergence from chimpanzees (Pollard et al., 2006a,b; Prabhakar et al., 2006; Bird et al., 2007; Bush and Lahn, 2008). These studies mainly focused on the discovery of changes in noncoding regions that have a high probability to be functional. Thus, these investigations analyzed genomic regions that are highly conserved in non-human species (mammals or vertebrates) but changed significantly in humans. Before the appearance of epigenetic marks that help in the identification of non-coding functional elements (ENCODE Project Consortium et al., 2007; Kellis et al., 2014), using this signature of negative selection in other species helped to identify putative regulatory sequences with constrained function (Schwartz et al., 2000; Ovcharenko et al., 2004; Siepel, 2005; Prabhakar et al., 2006). These studies collectively identified over 2,500 non-coding regions defined as Human Accelerated Regions (HARs) (Capra et al., 2013; Hubisz and Pollard, 2014), most of which were likely shaped by positive selection although some of them show signatures of non-selective mechanisms such as GC-biased gene conversion (Pollard et al., 2006a; Katzman et al., 2010; Ratnakumar et al., 2010; Sumiyama and Saitou, 2011; Kostka et al., 2012). Furthermore, similar approaches have also been used to analyze regions of the human genome that changed significantly since divergence from archaic hominins (Green et al., 2010). It was found that HARs are enriched for substitutions that antecede the split from Neanderthals and Denisovans, suggesting that our genome did not evolve especially rapidly in the course of the emergence of modern humans (Burbano et al., 2012; Hubisz and Pollard, 2014). HARs have a distinctive genomic distribution since they cluster nearby regulatory genes including transcription factors expressed during development (Capra et al., 2013; Kamm et al., 2013b). These findings suggest that HAR mutations could potentially lead to the modification of developmental gene regulatory networks and thus, underlie the evolution of unique human traits. Interestingly, the gene that accumulates the largest number of HAR in the human genome is the neurodevelopmental transcription factor NPAS3 (Neuronal PAS domain-containing protein 3), a gene that has been associated with several neurological diseases in humans (Pickard et al., 2005, 2009; Macintyre et al., 2010). In addition, NPAS3 is expressed in telencephalic progenitor domains of the cortex, and the caudal and medial ganglionic eminences (CGE and MGE, respectively), and later in immature and mature cortical interneurons (ErbelSieler et al., 2004; Batista-Brito et al., 2008). In fact, it has been shown that NPAS3 regulates neurogenesis in the brain and particularly that NPAS3 mutants display reduced numbers of interneurons in the cortex (Stanco et al., 2014). Moreover, it has been shown that 11 out of the 14 HARs located in NPAS 3 introns, were capable of driving reproducible expression of a reporter gene in the CNS of transgenic zebrafish (Kamm et al., 2013b). Further studies showed that one of these regions (2xHAR.142) drove the reporter gene LacZ expression to an extended region of the developing anterior telencephalon in comparison with the chimpanzee and mouse ortholog sequences when tested in transgenic mice (Kamm et al., 2013a). This is a salient example among the currently small catalog of regulatory regions carrying human-specific changes that likely modified human-specific expression patterns of brain developmental genes.

More recently, it has been also shown that HARs accumulate in a topologically associated domain encompassing the gene FOXP2 (Caporale et al., 2019). In fact, introns and intergenic regions of FOXP2 harbor 12 HARs, several of which act as transcriptional enhancers in the nervous system in expression assays in transgenic zebrafish and mice. Moreover, two of these regions drove the reporter gene to FOXP2 expressing cells in the developing brain and also display different expression patterns when compared with chimpanzee ortholog regions, indicating that the accelerated evolutionary process that they underwent in the human lineage are likely to have functional consequences (Caporale et al., 2019).

Boyd et al. (2015) have recently selected the HAR ANC516 previously identified (Bird et al., 2007) that they renamed as HARE5 for functional studies. This element located near the Wnt receptor Frizzled 8 (FZD8) gene displays differential enhancer activity in the developing cortex of transgenic mice (Boyd et al., 2015) depending on whether HARE5 was from human or chimpanzee origin. In fact, the human sequence drives reporter gene expression in a more robust way and 
in an earlier developmental time point than the ortholog chimpanzee sequence in the developing cortex. Then, the authors generated transgenic mice carrying the chimp or the human HARE5 sequences controlling the expression of the mouse Fzd8 coding sequence and analyzed comparatively several features of cortical development. Although this approach did not control for positional effects on the transgenics the results are worth to be mentioned. Overexpression of Fzd8 controlled by human HARE5 produced a faster cell cycle in neuronal progenitors and led to increased neocortical size compared with mice where Fzd8 is driven by chimpanzee HARE5 (Boyd et al., 2015). Although these results probably represent a step forward to understanding human brain evolution, further demonstration of how HARE5, NPAS3-HARs, or FOXP2-HARs impacted in human evolution still requires additional studies. An important issue to consider is that we still lack information about the expression pattern of FZD8, FOXP2, and NPAS3 in human and chimpanzee developing brains. Thus, we do not know if these genes are in fact differentially expressed in these two species. In addition, it would be very informative to generate genetically engineered mice strains carrying human versions of HARE5 and other differentially expressed HARs replacing their mouse ortholog region to then analyze brain size, neuronal cell counts, and cognitive and behavioral traits.

A recent study integrated previously identified threedimensional chromatin interaction map in developing human cortex (Won et al., 2019), which identified physical enhancerpromoter/gene interactions with HARs. This study identified the gene targets of HARs in the developing cortical plate of the human fetal cortex (Won et al., 2019). The authors found that the putative target genes of HARs are enriched in pathways involved in human brain development, dorsal-ventral patterning, cortical lamination, regionalization, and proliferation of neuronal progenitors which led them to suggest that multiple aspects of human brain development are subject to humanspecific regulation (Won et al., 2019).

\section{Genetics of Human Cognitive Abilities}

Regarding the genetics underlying the evolution of human cognitive abilities, in the last years some advances have been made into the identification of genetic loci relative to human cognitive function. In fact, Davies et al., found 148 genetic loci associated with general cognitive function using data from different large datasets like the UK biobank, CHARGE and COGENT consortia (Davies et al., 2018). Another recent study analyzed the expansion of cognitive networks in the human brain and the expression in these networks of genes associated to HARs (Wei et al., 2019). These authors found that HAR-associated genes are differentially expressed in higher-order cognitive networks in humans compared to chimpanzees and macaques (Wei et al., 2019). There is no doubt that these works will help to identify important genes and pathways that have played an important role into the evolution of our salient cognitive capacities.

\section{CONCLUDING REMARKS AND FUTURE DIRECTIONS}

Through this journey across the history of our cortex we can conclude that several key steps were necessary to render the mammalian neocortex that in some lineages reached a high degree of development and where highly-elaborated cognitive capacities are a distinctive feature. First, the appearance of the sixlayered neocortex that probably happened in an ancestor of all mammals before the split of monotremes approximately between 240 and 180 mya was a cornerstone in the evolution of the organization of the basic plan of the mammalian neocortex. In this plan, the SVZ plays a fundamental role in the development of this six-layered neocortex. Then, the split and specialization of the SVZ seems to be the developmental mechanism that allowed the appearance of species with a high degree of encephalization and gyrencephaly, although it seems that the ancestor of all mammals possessed a gyrencephalic brain. However, more comparative studies will be necessary to help us to complete the puzzle and to better understand the molecular and cellular mechanisms underlying the emergence of the mammalian brain first and then brains with salient cognitive capacities. We still know very little about the genetic differences that led to the appearance of mammals and to the evolution of the distinctive characters of this group, particularly its brain. In the last years the explosion of the genomic era and the availability of genome sequences of many species of mammals and other vertebrates has enabled genome-wide comparisons among species and to detect genetic changes that emerged across their evolution. However, we need to understand how these genomic changes translate into gene expression differences or protein function modifications. Thus, it is important to perform comparative functional studies among different species that will help us to understand the phenotypic consequences of these genetic changes.

In this regard, the recent incorporation of different reptile species as animal models is helping us to understand the particular characteristics of the reptile brain and perform comparative studies to mammals illuminating in this way key aspects of mammalian brain evolution (Nomura et al., 2013b). In this sense, the development in the last years of several technologies will help to disentangle the evolutionary history of the mammalian brain. For instance, the possibility of studying brain organoids instead of animal models that are somewhat complicated due to several reasons including difficulty in laboratory reproduction promise to be crucial into understanding better brain developmental mechanisms in several lineages (Lancaster and Knoblich, 2014; Qian et al., 2019). However, some aspects of the development of the cortex are difficult to model in brain organoids, thus, this technique has to be used with caution and should be combined with the use of in vivo models that allow to model development in a more real system (Marx, 2020). In this sense, recent improvements to the protocols used to culture brain organoids are making them more complex and dynamic incorporating aspects of development that better mimic in vivo conditions (Shou et al., 2020). Moreover, the recent implementation of brain organoids from different primates is allowing us to model human brain evolution in a dish 
and to better understand how genetic differences translate into gene expression and phenotypic differences (Pollen et al., 2019).

In addition, high-throughput sequencing techniques such as RNAseq are allowing to perform comparisons of transcriptional landscapes of different species and thus pinpoint some fundamental genetic pathways that were modified in the different lineages. Moreover, single-cell RNAseq gives the possibility of exploring the gene expression program of a given cell and then comparing particular kinds of cells across different species. These techniques promise in the near future to help us understand the different genetic pathways that are activated in different cells across species to render differences in brain development.

Moreover, the development of CRISPR/Cas technologies that allow to genetically engineer almost any organisms (Gilbert et al., 2014; Zheng et al., 2014) will be crucial to understand how lineage-specific genetic

\section{REFERENCES}

Aboitiz, F., and Montiel, J. (2003). One hundred million years of interhemispheric communication: the history of the corpus callosum. Braz. J. Med. Biol. Res. 36, 409-420. doi: 10.1590/S0100-879X2003000400002

Aboitiz, F., Montiel, J., and López, J. (2002). Critical steps in the early evolution of the isocortex: insights from developmental biology. Braz. J. Med. Biol. Res. 35, 1455-1472. doi: 10.1590/S0100-879X2002001200006

Agirman, G., Broix, L., and Nguyen, L. (2017). Cerebral cortex development: an outside-in perspective. FEBS Lett. 591, 3978-3992. doi: 10.1002/1873-3468.12924

Albert, M., and Huttner, W. B. (2015). Clever space saving-how the cerebral cortex folds. EMBO J. 34, 1845-1847. doi: 10.15252/embj.201591952

Allen, J., Weinrich, M., Hoppitt, W., and Rendell, L. (2013). Network-based diffusion analysis reveals cultural transmission of lobtail feeding in humpback whales. Science 340, 485-488. doi: 10.1126/science.1231976

Allman, J. M. (1999). Evolving Brains. New York, NY: Scientific American Library.

Allman, J. M., Tetreault, N. A., Hakeem, A. Y., Manaye, K. F., Semendeferi, K., Erwin, J. M., et al. (2010). The von Economo neurons in frontoinsular and anterior cingulate cortex in great apes and humans. Brain Struct. Funct. 214, 495-517. doi: 10.1007/s00429-010-0254-0

Allman, J. M., Watson, K. K., Tetreault, N. A., and Hakeem, A. Y. (2005). Intuition and autism: a possible role for Von Economo neurons. Trends Cogn. Sci. 9, 367-373. doi: 10.1016/j.tics.2005.06.008

Andrews, W., Liapi, A., Plachez, C., Camurri, L., Zhang, J., Mori, S., et al. (2006). Robol regulates the development of major axon tracts and interneuron migration in the forebrain. Development 133, 2243-2252. doi: 10.1242/dev.02379

Antonacci, F., Dennis, M. Y., Huddleston, J., Sudmant, P. H., Steinberg, K. M., Rosenfeld, J. A., et al. (2014). Palindromic GOLGA8 core duplicons promote chromosome 15q13.3 microdeletion and evolutionary instability. Nat. Genet. 46, 1293-1302. doi: 10.1038/ng.3120

Armengol, G., Knuutila, S., Lozano, J.-J., Madrigal, I., and Caballín, M.-R. (2010). Identification of human specific gene duplications relative to other primates by array CGH and quantitative PCR. Genomics 95, 203-209. doi: 10.1016/j.ygeno.2010.02.003

Ashwell, K. W. S., and Hardman, C. D. (2012). Distinct development of the cerebral cortex in platypus and echidna. Brain Behav. Evol. 79, 57-72. doi: 10.1159/000334188

Atkinson, E. G., Audesse, A. J., Palacios, J. A., Bobo, D. M., Webb, A. E., Ramachandran, S., et al. (2018). No evidence for recent selection at FOXP2 among diverse human populations. Cell 174, 1424-1435.e15. doi: 10.1016/j.cell.2018.06.048 modifications can impact on molecular pathways to finally render anatomic and functional changes in the mammalian cortex.

Finally, all this development in technology will help us to advance in knowledge and to better understand an essential piece of mammalian evolution: the mammalian brain.

\section{AUTHOR CONTRIBUTIONS}

The author confirms being the sole contributor of this work and has approved it for publication.

\section{FUNDING}

This work was supported by PICT-2018-02216 from Agencia Nacional de Promoción Científica y Tecnológica de Argentina (ANPCyT).
Azevedo, F. A. C., and Carvalho, L. R. B. (2009). Equal numbers of neuronal and nonneuronal cells make the human brain an isometrically scaled-up primate brain. J Comp Neurol. 513, 532-541. doi: 10.1002/cne. 21974

Azim, E., Jabaudon, D., Fame, R. M., and Macklis, J. D. (2009). SOX6 controls dorsal progenitor identity and interneuron diversity during neocortical development. Nat. Neurosci. 12, 1238-1247. doi: 10.1038/nn.2387

Bae, B.-I., Jayaraman, D., and Walsh, C. A. (2015). Genetic changes shaping the human brain. Dev. Cell 32, 423-434. doi: 10.1016/j.devcel.2015.01.035

Bar, I., Lambert de Rouvroit, C., and Goffinet, A. M. (2000). The evolution of cortical development. An hypothesis based on the role of the Reelin signaling pathway. Trends Neurosci. 23, 633-638. doi: 10.1016/S0166-2236(00)01675-1

Bartolini, G., Sánchez-Alcañiz, J. A., Osório, C., Valiente, M., García-Frigola, C., and Marín, O. (2017). Neuregulin 3 mediates cortical plate invasion and laminar allocation of GABAergic interneurons. Cell Rep. 18, 1157-1170. doi: 10.1016/j.celrep.2016.12.089

Barton, R. A., and Venditti, C. (2013a). Human frontal lobes are not relatively large. Proc. Natl. Acad. Sci. U.S. A. 110, 9001-9006. doi: 10.1073/pnas.1215723110

Barton, R. A., and Venditti, C. (2013b). Reply to smaers: getting human frontal lobes in proportion. Proc. Natl. Acad. Sci. U.S. A. 110, E3683-E3684. doi: 10.1073/pnas. 1310334110

Batista-Brito, R., Machold, R., Klein, C., and Fishell, G. (2008). Gene expression in cortical interneuron precursors is prescient of their mature function. Cereb. Cortex 18, 2306-2317. doi: 10.1093/cercor/bhm 258

Batista-Brito, R., Rossignol, E., Hjerling-Leffler, J., Denaxa, M., Wegner, M., Lefebvre, V., et al. (2009). The cell-intrinsic requirement of Sox6 for cortical interneuron development. Neuron 63, 466-481. doi: 10.1016/j.neuron.2009.08.005

Baudoin, J.-P., Viou, L., Launay, P.-S., Luccardini, C., Espeso Gil, S., Kiyasova, V., et al. (2012). Tangentially migrating neurons assemble a primary cilium that promotes their reorientation to the cortical plate. Neuron 76, 1108-1122. doi: 10.1016/j.neuron.2012.10.027

Bayly, P. V., Taber, L. A., and Kroenke, C. D. (2014). Mechanical forces in cerebral cortical folding: a review of measurements and models. J. Mech. Behav. Biomed. Mater. 29, 568-581. doi: 10.1016/j.jmbbm.2013.02.018

Benton, M. J. (2015). Palaeodiversity and formation counts: redundancy or bias? Palaeontology 58, 1003-1029. doi: 10.1111/pala.12191

Benton, M. J., Donoghue, P. C. J., Asher, R. J., Friedman, M., Near, T. J., and Vinther, J. (2015). Constraints on the timescale of animal evolutionary history. Palaeontol. Electronica 18, 1-106. doi: 10.26879/424

Bernier, B., Bar, I., D’Arcangelo, G., Curran, T., and Goffinet, A. M. (2000). Reelin mRNA expression during embryonic brain development in the chick. J. Comp. Neurol. 422, 448-463. 
Bernier, B., Bar, I., Pieau, C., Lambert De Rouvroit, C., and Goffinet, A. M. (1999). Reelin mRNA expression during embryonic brain development in the turtle Emys orbicularis. J. Comp. Neurol. 413, 463-479.

Berto, S., and Nowick, K. (2018). Species-specific changes in a primate transcription factor network provide insights into the molecular evolution of the primate prefrontal cortex. Genome Biol. Evol. 10, 2023-2036. doi: $10.1093 /$ gbe/evy149

Bielle, F., Griveau, A., Narboux-Nême, N., Vigneau, S., Sigrist, M., Arber, S., et al. (2005). Multiple origins of Cajal-Retzius cells at the borders of the developing pallium. Nat. Neurosci. 8, 1002-1012. doi: 10.1038/nn1511

Bird, C. P., Stranger, B. E., Liu, M., Thomas, D. J., Ingle, C. E., Beazley, C., et al. (2007). Fast-evolving noncoding sequences in the human genome. Genome Biol. 8:R118. doi: 10.1186/gb-2007-8-6-r118

Bond, A. M., Bhalala, O. G., and Kessler, J. A. (2012). The dynamic role of bone morphogenetic proteins in neural stem cell fate and maturation. Dev. Neurobiol. 72, 1068-1084. doi: 10.1002/dneu.22022

Borrell, V. (2018). How cells fold the cerebral cortex. J. Neurosci. 38, 776-783. doi: 10.1523/JNEUROSCI.1106-17.2017

Boyd, J. L., Skove, S. L., Rouanet, J. P., Pilaz, L.-J., Bepler, T., Gordân, R., et al. (2015). Human-chimpanzee differences in a FZD8 enhancer alter cell-cycle dynamics in the developing neocortex. Curr. Biol. 25, 772-779. doi: 10.1016/j.cub.2015.01.041

Britten, R. J. (2002). Divergence between samples of chimpanzee and human DNA sequences is 5\%, counting indels. Proc. Natl. Acad. Sci. U.S.A. 99, 13633-13635. doi: $10.1073 /$ pnas. 172510699

Brown, K. N., Chen, S., Han, Z., Lu, C.-H., Tan, X., Zhang, X.-J., et al. (2011). Clonal production and organization of inhibitory interneurons in the neocortex. Science 334, 480-486. doi: 10.1126/science.1208884

Bruce, L. (2010). "Evolution of the nervous system in reptiles," in Evolution of Nervous Systems, ed J. H. Kaas (Oxford, UK: Elsevier Inc.), 125-156.

Buchsbaum, I. Y., and Cappello, S. (2019). Neuronal migration in the CNS during development and disease: insights from in vivo and in vitro models. Development 146:dev163766. doi: 10.1242/dev.163766

Burbano, H. A., Green, R. E., Maricic, T., Lalueza-Fox, C., de la Rasilla, M., Rosas, A., et al. (2012). Analysis of human accelerated DNA regions using archaic hominin genomes. PLoS ONE 7:e32877. doi: 10.1371/journal.pone.0032877

Bush, E. C., and Lahn, B. T. (2008). A genome-wide screen for noncoding elements important in primate evolution. BMC Evol. Biol. 8:17. doi: 10.1186/1471-2148-8-17

Bustamante, C. D., Fledel-Alon, A., Williamson, S., Nielsen, R., Hubisz, M. T., Glanowski, S., et al. (2005). Natural selection on protein-coding genes in the human genome. Nature 437, 1153-1157. doi: 10.1038/nature04240

Butler, A. B., Reiner, A., and Karten, H. J. (2011). Evolution of the amniote pallium and the origins of mammalian neocortex. Ann. N. Y. Acad. Sci. 1225, 14-27. doi: $10.1111 / j .1749-6632.2011 .06006 . x$

Butt, S. J. B., Sousa, V. H., Fuccillo, M. V., Hjerling-Leffler, J., Miyoshi, G., Kimura, S., et al. (2008). The requirement of $\mathrm{Nkx2-1}$ in the temporal specification of cortical interneuron subtypes. Neuron 59, 722-732. doi: 10.1016/j.neuron.2008.07.031

Butti, C., Sherwood, C. C., Hakeem, A. Y., Allman, J. M., and Hof, P. R. (2009). Total number and volume of Von Economo neurons in the cerebral cortex of cetaceans. J. Comp. Neurol. 515, 243-259. doi: 10.1002/cne.22055

Cabrera-Socorro, A., Hernandez-Acosta, N. C., Gonzalez-Gomez, M., and Meyer, G. (2007). Comparative aspects of p73 and Reelin expression in Cajal-Retzius cells and the cortical hem in lizard, mouse and human. Brain Res. 1132, 59-70. doi: 10.1016/j.brainres.2006.11.015

Cantalupo, C., and Hopkins, W. D. (2001). Asymmetric Broca's area in great apes. Nature 414:505. doi: 10.1038/35107134

Caporale, A. L., Gonda, C. M., and Franchini, L. F. (2019). Transcriptional enhancers in the FOXP2 locus underwent accelerated evolution in the human lineage. Mol. Biol. Evol. 36, 2432-2450. doi: 10.1093/molbev/msz173

Capra, J. A., Erwin, G. D., McKinsey, G., Rubenstein, J. L. R., and Pollard, K. S. (2013). Many human accelerated regions are developmental enhancers. Philos. Trans. R. Soc. Lond. B Biol. Sci. 368:20130025. doi: 10.1098/rstb.2013.0025

Cárdenas, A., Villalba, A., de Juan Romero, C., Picó, E., Kyrousi, C., Tzika, A. C., et al. (2018). Evolution of cortical neurogenesis in amniotes controlled by robo signaling levels. Cell 174, 590-606.e21. doi: 10.1016/j.cell.2018.06.007
Charrier, C., Joshi, K., Coutinho-Budd, J., Kim, J.-E., Lambert, N., de Marchena, J., et al. (2012). Inhibition of SRGAP2 function by its human-specific paralogs induces neoteny during spine maturation. Cell 149, 923-935. doi: 10.1016/j.cell.2012.03.034

Chenn, A., and Walsh, C. A. (2002). Regulation of cerebral cortical size by control of cell cycle exit in neural precursors. Science 297, 365-369. doi: $10.1126 /$ science. 1074192

Cheung, A. F. P., Kondo, S., Abdel-Mannan, O., Chodroff, R. A., Sirey, T. M., Bluy, L. E., et al. (2010). The subventricular zone is the developmental milestone of a 6-layered neocortex: comparisons in metatherian and eutherian mammals. Cereb. Cortex 20, 1071-1081. doi: 10.1093/cercor/bhp168

Cheung, A. F. P., Pollen, A. A., Tavare, A., DeProto, J., and Molnár, Z. (2007). Comparative aspects of cortical neurogenesis in vertebrates. J. Anat. 211, 164-176. doi: 10.1111/j.1469-7580.2007.00769.x

Chiang, C., Swan, R. Z., Grachtchouk, M., Bolinger, M., Litingtung, Y., Robertson, E. K., et al. (1999). Essential role for Sonic hedgehog during hair follicle morphogenesis. Dev. Biol. 205, 1-9. doi: 10.1006/dbio.199 8.9103

Chimpanzee Sequencing and Analysis Consortium (2005). Initial sequence of the chimpanzee genome and comparison with the human genome. Nature 437, 69-87. doi: 10.1038/nature04072

Ciceri, G., Dehorter, N., Sols, I., Huang, Z. J., Maravall, M., and Marín, O. (2013). Lineage-specific laminar organization of cortical GABAergic interneurons. Nat. Neurosci. 16, 1199-1210. doi: 10.1038/nn.3485

Clark, A. G., Glanowski, S., Nielsen, R., Thomas, P. D., Kejariwal, A., Todd, M. A., et al. (2003). Inferring nonneutral evolution from human-chimp-mouse orthologous gene trios. Science 302, 1960-1963. doi: 10.1126/science.1088821

Coe, B. P., Witherspoon, K., Rosenfeld, J. A., van Bon, B. W. M., Vulto-van Silfhout, A. T., Bosco, P., et al. (2014). Refining analyses of copy number variation identifies specific genes associated with developmental delay. Nat. Genet. 46, 1063-1071. doi: 10.1038/ng.3092

Colbert, E. H., Minkoff, E. C., and Morales, M. (2001). Colbert's Evolution of the Vertebrates: A History of the Backboned Animals Through Time. Hoboken, NJ: Wiley-Liss \& Sons.

Connor, R. C. (2007). Dolphin social intelligence: complex alliance relationships in bottlenose dolphins and a consideration of selective environments for extreme brain size evolution in mammals. Philos. Transac. R. Soc. B Biol. Sci. 362, 587-602. doi: 10.1098/rstb.2006.1997

Corbit, K. C., Aanstad, P., Singla, V., Norman, A. R., Stainier, D. Y. R., and Reiter, J. F. (2005). Vertebrate Smoothened functions at the primary cilium. Nature 437, 1018-1021. doi: 10.1038/nature04117

D'Arcangelo, G. (2005). The reeler mouse: anatomy of a mutant. Int. Rev. Neurobiol. 71, 383-417. doi: 10.1016/S0074-7742(05)71016-3

Davies, G., Lam, M., Harris, S. E., Trampush, J. W., Luciano, M., Hill, W. D., et al. (2018). Study of 300,486 individuals identifies 148 independent genetic loci influencing general cognitive function. Nat. Commun. 9:2098. doi: 10.1038/s41467-018-04362-x

Dehay, C., Kennedy, H., and Kosik, K. S. (2015). The outer subventricular zone and primate-specific cortical complexification. Neuron 85, 683-694. doi: 10.1016/j.neuron.2014.12.060

Dennis, M. Y., Nuttle, X., Sudmant, P. H., Antonacci, F., Graves, T. A., Nefedov, M., et al. (2012). Evolution of human-specific neural SRGAP2 genes by incomplete segmental duplication. Cell 149, 912-922. doi: 10.1016/j.cell.2012.03.033

Derynck, R., and Zhang, Y. E. (2003). Smad-dependent and Smadindependent pathways in TGF-beta family signalling. Nature 425, 577-584. doi: 10.1038/nature02006

Doggett, N. A., Xie, G., Meincke, L. J., Sutherland, R. D., Mundt, M. O., Berbari, N. S., et al. (2006). A 360-kb interchromosomal duplication of the human HYDIN locus. Genomics 88, 762-771. doi: 10.1016/j.ygeno.2006.07.012

Dorus, S., Anderson, J. R., Vallender, E. J., Gilbert, S. L., Zhang, L., Chemnick, L. G., et al. (2006). Sonic Hedgehog, a key development gene, experienced intensified molecular evolution in primates. Hum. Mol. Genet. 15, 2031-2037. doi: $10.1093 / \mathrm{hmg} / \mathrm{ddl} 123$

Dorus, S., Vallender, E. J., Evans, P. D., Anderson, J. R., Gilbert, S. L., Mahowald, M., et al. (2004). Accelerated evolution of nervous system genes in the origin of Homo sapiens. Cell 119, 1027-1040. doi: 10.1016/j.cell.2004. 11.040 
Dugas-Ford, J., Rowell, J. J., and Ragsdale, C. W. (2012). Cell-type homologies and the origins of the neocortex. Proc. Natl. Acad. Sci. U.S.A. 109, 16974-16979. doi: $10.1073 /$ pnas. 1204773109

Dumas, L., and Sikela, J. M. (2009). DUF1220 domains, cognitive disease, and human brain evolution. Cold Spring Harb. Symp. Quant. Biol. 74, 375-382. doi: 10.1101/sqb.2009.74.025

Dunwell, T. L., Paps, J., and Holland, P. W. H. (2017). Novel and divergent genes in the evolution of placental mammals. Proc. Biol. Sci. 284:20171357. doi: $10.1098 / \mathrm{rspb} .2017 .1357$

Echelard, Y., Epstein, D. J., St-Jacques, B., Shen, L., Mohler, J., McMahon, J. A., et al. (1993). Sonic hedgehog, a member of a family of putative signaling molecules, is implicated in the regulation of CNS polarity. Cell 75, 1417-1430. doi: 10.1016/0092-8674(93)90627-3

Elias, L. A. B., Turmaine, M., Parnavelas, J. G., and Kriegstein, A. R. (2010). Connexin 43 mediates the tangential to radial migratory switch in ventrally derived cortical interneurons. J. Neurosci. 30, 7072-7077. doi: 10.1523/JNEUROSCI.5728-09.2010

Enard, W., Gehre, S., Hammerschmidt, K., Hölter, S. M., Blass, T., Somel, M., et al. (2009). A humanized version of Foxp2 affects cortico-basal ganglia circuits in mice. Cell 137, 961-971. doi: 10.1016/j.cell.2009.03.041

Enard, W., Przeworski, M., Fisher, S. E., Lai, C. S. L., Wiebe, V., Kitano, T., et al. (2002). Molecular evolution of FOXP2, a gene involved in speech and language. Nature 418, 869-872. doi: 10.1038/nature01025

ENCODE Project Consortium, Birney, E., Stamatoyannopoulos, J. A., Dutta, A., Guigó, R., Gingeras, T. R., et al. (2007). Identification and analysis of functional elements in $1 \%$ of the human genome by the ENCODE pilot project. Nature 447, 799-816. doi: 10.1038/nature05874

Erbel-Sieler, C., Dudley, C., Zhou, Y., Wu, X., Estill, S. J., Han, T., et al. (2004). Behavioral and regulatory abnormalities in mice deficient in the NPAS1 and NPAS3 transcription factors. Proc. Natl. Acad. Sci. U.S.A. 101, 13648-13653. doi: 10.1073/pnas.0405310101

Ericson, J., Muhr, J., Placzek, M., Lints, T., Jessell, T. M., and Edlund, T. (1995). Sonic hedgehog induces the differentiation of ventral forebrain neurons: a common signal for ventral patterning within the neural tube. Cell 81, 747-756. doi: 10.1016/0092-8674(95)90536-7

Faux, C., Rakic, S., Andrews, W., and Britto, J. M. (2012). Neurons on the move: migration and lamination of cortical interneurons. Neurosignals 20, 168-189. doi: $10.1159 / 000334489$

Fiddes, I. T., Lodewijk, G. A., Mooring, M., Bosworth, C. M., Ewing, A. D., Mantalas, G. L., et al. (2018). Human-specific NOTCH2NL genes affect notch signaling and cortical neurogenesis. Cell 173, 1356-1369.e22. doi: 10.1016/j.cell.2018.03.051

Fietz, S. A., Kelava, I., Vogt, J., Wilsch-Bräuninger, M., Stenzel, D., Fish, J. L., et al. (2010). OSVZ progenitors of human and ferret neocortex are epithelial-like and expand by integrin signaling. Nat. Neurosci. 13, 690-699. doi: 10.1038/nn.2553

Fisher, S. E. (2019). Human genetics: the evolving story of FOXP2. Curr. Biol. 29, R65-R67. doi: 10.1016/j.cub.2018.11.047

Florio, M., Albert, M., Taverna, E., Namba, T., Brandl, H., Lewitus, E., et al. (2015). Human-specific gene ARHGAP11B promotes basal progenitor amplification and neocortex expansion. Science 347, 1465-1470. doi: 10.1126/science.aaa1975

Florio, M., Heide, M., Pinson, A., Brandl, H., Albert, M., Winkler, S., et al. (2018). Evolution and cell-type specificity of human-specific genes preferentially expressed in progenitors of fetal neocortex. Elife 7:e32332. doi: $10.7554 /$ eLife. 32332.045

Florio, M., and Huttner, W. B. (2014). Neural progenitors, neurogenesis and the evolution of the neocortex. Development 141, 2182-2194. doi: 10.1242/dev.090571

Florio, M., Namba, T., Pääbo, S., Hiller, M., and Huttner, W. B. (2016). A single splice site mutation in human-specific ARHGAP11B causes basal progenitor amplification. Sci. Adv. 2:e1601941. doi: 10.1126/sciadv.1601941

Fortna, A., Kim, Y., MacLaren, E., Marshall, K., Hahn, G., Meltesen, L., et al. (2004). Lineage-specific gene duplication and loss in human and great ape evolution. PLoS Biol. 2:e207. doi: 10.1371/journal.pbio.0020207

Fox, K. C. R., Muthukrishna, M., and Shultz, S. (2017). The social and cultural roots of whale and dolphin brains. Nat. Ecol. Evol. 1, 1699-1705. doi: 10.1038/s41559-017-0336-y

Franchini, L. F., López-Leal, R., Nasif, S., Beati, P., Gelman, D. M., Low, M. J., et al. (2011). Convergent evolution of two mammalian neuronal enhancers by sequential exaptation of unrelated retroposons. Proc. Natl. Acad. Sci. U.S.A. 108, 15270-15275. doi: 10.1073/pnas.1104997108

Franchini, L. F., and Pollard, K. S. (2017). Human evolution: the non-coding revolution. BMC Biol. 15:89. doi: 10.1186/s12915-017-0428-9

Fuccillo, M., Rallu, M., McMahon, A. P., and Fishell, G. (2004). Temporal requirement for hedgehog signaling in ventral telencephalic patterning. Development 131, 5031-5040. doi: 10.1242/dev.01349

Fukuchi-Shimogori, T., and Grove, E. A. (2001). Neocortex patterning by the secreted signaling molecule FGF8. Science 294, 1071-1074. doi: $10.1126 /$ science.1064252

Garel, S., Huffman, K. J., and Rubenstein, J. L. R. (2003). Molecular regionalization of the neocortex is disrupted in Fgf8 hypomorphic mutants. Development 130, 1903-1914. doi: 10.1242/dev.00416

Gelman, D. M., and Marín, O. (2010). Generation of interneuron diversity in the mouse cerebral cortex. Eur. J. Neurosci. 31, 2136-2141. doi: 10.1111/j.1460-9568.2010.07267.x

Germain, N., Banda, E., and Grabel, L. (2010). Embryonic stem cell neurogenesis and neural specification. J. Cell. Biochem. 111, 535-542. doi: 10.1002/jcb.22747

Gilbert, L. A., Horlbeck, M. A., Adamson, B., Villalta, J. E., Chen, Y., Whitehead, E. H., et al. (2014). Genome-scale CRISPR-mediated control of gene repression and activation. Cell 159, 647-661. doi: 10.1016/j.cell.2014.09.029

Girirajan, S., Campbell, C. D., and Eichler, E. E. (2011). Human copy number variation and complex genetic disease. Ann. Rev. Genet. 45, 203-226. doi: 10.1146/annurev-genet-102209-163544

Girirajan, S., Dennis, M. Y., Baker, C., Malig, M., Coe, B. P., Campbell, C. D., et al. (2013). Refinement and discovery of new hotspots of copy-number variation associated with autism spectrum disorder. Am. J. Hum. Genet. 92, 221-237. doi: 10.1016/j.ajhg.2012.12.016

Goffinet, A. M. (2017). The evolution of cortical development: the synapsiddiapsid divergence. Development 144, 4061-4077. doi: 10.1242/dev.153908

Goffinet, A. M., Bar, I., Bernier, B., Trujillo, C., Raynaud, A., and Meyer, G. (1999). Reelin expression during embryonic brain development in lacertilian lizards. $J$. Comp. Neurol. 414, 533-550.

Goffinet, A. M., Daumerie, C., Langerwerf, B., and Pieau, C. (1986). Neurogenesis in reptilian cortical structures: $3 \mathrm{H}$-thymidine autoradiographic analysis. $J$. Comp. Neurol. 243, 106-116. doi: 10.1002/cne.902430109

Goidts, V., Cooper, D. N., Armengol, L., Schempp, W., Conroy, J., Estivill, X., et al. (2006). Complex patterns of copy number variation at sites of segmental duplications: an important category of structural variation in the human genome. Hum. Genet. 120, 270-284. doi: 10.1007/s00439-006-0217-y

Gonda, Y., Andrews, W. D., Tabata, H., Namba, T., Parnavelas, J. G., Nakajima, K., et al. (2013). Robol regulates the migration and laminar distribution of upperlayer pyramidal neurons of the cerebral cortex. Cereb. Cortex 23, 1495-1508. doi: $10.1093 /$ cercor/bhs141

Goodman, M. (1999). The genomic record of Humankind's evolutionary roots. Am. J. Hum. Genet. 64, 31-39. doi: 10.1086/302218

Green, R. E., Krause, J., Briggs, A. W., Maricic, T., Stenzel, U., Kircher, M., et al. (2010). A draft sequence of the Neandertal genome. Science 328, 710-722. doi: 10.1126/science.1188021

Guerrier, S., Coutinho-Budd, J., Sassa, T., Gresset, A., Jordan, N. V., Chen, K., et al. (2009). The F-BAR domain of srGAP2 induces membrane protrusions required for neuronal migration and morphogenesis. Cell 138, 990-1004. doi: 10.1016/j.cell.2009.06.047

Hahn, M. W., Demuth, J. P., and Han, S.-G. (2007). Accelerated rate of gene gain and loss in primates. Genetics 177, 1941-1949. doi: 10.1534/genetics.107.080077

Hakeem, A. Y., Sherwood, C. C., Bonar, C. J., Butti, C., Hof, P. R., and Allman, J. M. (2009). Von Economo neurons in the elephant brain. Anat. Rec. 292, 242-248. doi: 10.1002/ar.20829

Hammerschmidt, K., Schreiweis, C., Minge, C., Pääbo, S., Fischer, J., and Enard, W (2015). A humanized version of Foxp2 does not affect ultrasonic vocalization in adult mice. Genes Brain Behav. 14, 583-590. doi: 10.1111/gbb.12237

Hammond, V., So, E., Gunnersen, J., Valcanis, H., Kalloniatis, M., and Tan, S.-S. (2006). Layer positioning of late-born cortical interneurons is dependent on Reelin but not p35 signaling. J. Neurosci. 26, 1646-1655. doi: 10.1523/JNEUROSCI.3651-05.2006

Han, M. V., Demuth, J. P., McGrath, C. L., Casola, C., and Hahn, M. W. (2009). Adaptive evolution of young gene duplicates in mammals. Genome Res. 19, 859-867. doi: 10.1101/gr.085951.108 
Hansen, D. V., Lui, J. H., Parker, P. R. L., and Kriegstein, A. R. (2010). Neurogenic radial glia in the outer subventricular zone of human neocortex. Nature 464, 554-561. doi: 10.1038/nature08845

Harrison-Uy, S. J., and Pleasure, S. J. (2012). Wnt signaling and forebrain development. Cold Spring Harb. Perspect. Biol. 4:a008094. doi: 10.1101/cshperspect.a008094

Hart, B. L., and Hart, L. A. (2007). Evolution of the elephant brain: a paradox between brain size and cognitive behavior. Evol. Nervous Syst. 3, 261-266. doi: 10.1016/B0-12-370878-8/00343-8

Heide, M., Haffner, C., Murayama, A., Kurotaki, Y., Shinohara, H., Okano, H., et al. (2020). Human-specific ARHGAP11B increases size and folding of primate neocortex in the fetal marmoset. Science 369, 546-550. doi: 10.1126/science.abb2401

Heng, X., Guo, Q., Leung, A. W., and Li, J. Y. (2017). Analogous mechanism regulating formation of neocortical basal radial glia and cerebellar Bergmann glia. Elife 6:e23253. doi: 10.7554/eLife.232 53.044

Herculano-Houzel, S. (2009). The human brain in numbers: a linearly scaledup primate brain. Front. Hum. Neurosci. 3:31. doi: 10.3389/neuro.09.03 1.2009

Herculano-Houzel, S. (2012). The remarkable, yet not extraordinary, human brain as a scaled-up primate brain and its associated cost. Proc. Natl. Acad. Sci. U.S.A. 109(Suppl. 1), 10661-10668. doi: 10.1073/pnas.1201895109

Herculano-Houzel, S., Avelino-de-Souza, K., Neves, K., Porfírio, J., Messeder, D., Mattos Feijó, L., et al. (2014). The elephant brain in numbers. Front. Neuroanat. 8:46. doi: 10.3389/fnana.2014.00046

Herculano-Houzel, S., Collins, C. E., Wong, P., and Kaas, J. H. (2007). Cellular scaling rules for primate brains. Proc. Natl. Acad. Sci. U.S.A. 104, 3562-3567. doi: 10.1073/pnas.0611396104

Herculano-Houzel, S., and Kaas, J. H. (2011). Gorilla and orangutan brains conform to the primate cellular scaling rules: implications for human evolution. Brain Behav. Evol. 77, 33-44. doi: 10.1159/000322729

Hernandez-Miranda, L. R., Cariboni, A., Faux, C., Ruhrberg, C., Cho, J. H., Cloutier, J.-F., et al. (2011). Robol regulates semaphorin signaling to guide the migration of cortical interneurons through the ventral forebrain. J. Neurosci. 31, 6174-6187. doi: 10.1523/JNEUROSCI.5464-10.2011

Hevner, R. F. (2019). Intermediate progenitors and Tbr2 in cortical development. J. Anat. 235, 616-625. doi: 10.1111/joa.12939

Hevner, R. F., Daza, R. A. M., Englund, C., Kohtz, J., and Fink, A. (2004). Postnatal shifts of interneuron position in the neocortex of normal and reeler mice: evidence for inward radial migration. Neuroscience 124, 605-618. doi: 10.1016/j.neuroscience.2003.11.033

Hof, P. R., and Van Der Gucht, E. (2007). Structure of the cerebral cortex of the humpback whale, Megaptera novaeangliae (Cetacea, Mysticeti, Balaenopteridae). Anat. Rec. Adv. Integr. Anat. Evol. Biol. 290, 1-31. doi: 10.1002/ar.20407

Holloway, A. K., Bruneau, B. G., Sukonnik, T., Rubenstein, J. L., and Pollard, K. S. (2016). Accelerated evolution of enhancer hotspots in the mammal ancestor. Mol. Biol. Evol. 33, 1008-1018. doi: 10.1093/molbev/msv344

Hopson, J. A. (2001). “Origin of Mammals," in Palaeobiology II, eds D. E. G. Briggs and P. R. Crowther (Malden, MA: Blackwell Science Ltd), 88-94.

Hu, J. S., Vogt, D., Sandberg, M., and Rubenstein, J. L. (2017). Cortical interneuron development: a tale of time and space. Development 144, 3867-3878. doi: $10.1242 /$ dev.132852

Huang, X., Liu, J., Ketova, T., Fleming, J. T., Grover, V. K., Cooper, M. K., et al. (2010). Transventricular delivery of Sonic hedgehog is essential to cerebellar ventricular zone development. Proc. Natl. Acad. Sci. U.S.A. 107, 8422-8427. doi: 10.1073/pnas.0911838107

Hubisz, M. J., and Pollard, K. S. (2014). Exploring the genesis and functions of Human Accelerated Regions sheds light on their role in human evolution. Curr. Opin. Genet. Dev. 29, 15-21. doi: 10.1016/j.gde.2014.07.005

International Human Genome Sequencing Consortium (2004). Finishing the euchromatic sequence of the human genome. Nature 431, 931-945. doi: 10.1038/nature03001

Iskow, R. C., Gokcumen, O., and Lee, C. (2012). Exploring the role of copy number variants in human adaptation. Trends Genet. 28, 245-257. doi: 10.1016/j.tig.2012.03.002
Jakovcevski, I., Mayer, N., and Zecevic, N. (2011). Multiple origins of human neocortical interneurons are supported by distinct expression of transcription factors. Cerebral Cortex 21, 1771-1782. doi: 10.1093/cercor/bhq245

Jauch, A., Wienberg, J., Stanyon, R., Arnold, N., Tofanelli, S., Ishida, T., et al. (1992). Reconstruction of genomic rearrangements in great apes and gibbons by chromosome painting. Proc. Natl. Acad. Sci. U.S.A. 89, 8611-8615. doi: 10.1073/pnas.89.18.8611

Ji, Q., Luo, Z.-X., Yuan, C.-X., and Tabrum, A. R. (2006). A swimming mammaliaform from the Middle Jurassic and ecomorphological diversification of early mammals. Science 311, 1123-1127. doi: 10.1126/science.1123026

Ju, X.-C., Hou, Q.-Q., Sheng, A.-L., Wu, K.-Y., Zhou, Y., Jin, Y., et al. (2016). The hominoid-specific gene TBC1D3 promotes generation of basal neural progenitors and induces cortical folding in mice. Elife 5:e18197. doi: $10.7554 /$ eLife. 18197

Kaas, J. H. (2007). The evolution of sensory and motor systems in primates. Evol. Nervous Syst. 4, 35-57. doi: 10.1016/B0-12-370878-8/00002-1

Kaas, J. H. (2008). The evolution of the complex sensory and motor systems of the human brain. Brain Res. Bull. 75, 384-390. doi: 10.1016/j.brainresbull.2007.10.009

Kaas, J. H. (2012a). Evolution of columns, modules, and domains in the neocortex of primates. Proc. Natl. Acad. Sci. U.S.A. 109(Suppl. 1), 10655-10660. doi: 10.1073/pnas.1201892109

Kaas, J. H. (2012b). “The evolution of neocortex in primates," in Progress in Brain Research, eds M. A. Hofman and D. Falk (Amsterdan: Elsevier), 91-102.

Kaas, J. H. (2013). The evolution of brains from early mammals to humans. Wiley Interdiscip. Rev. Cogn. Sci. 4, 33-45. doi: 10.1002/wcs.1206

Kaas, J. H. (2020). "The organization of neocortex in early mammals," in Evolutionary Neuroscience, ed J. Kaas (Elsevier), 333-348. doi: 10.1016/B978-0-12-820584-6.00013-1

Kageyama, R., Ohtsuka, T., and Kobayashi, T. (2008). Roles of Hes genes in neural development. Dev. Growth Differ. 50(Suppl. 1), S97-S103. doi: 10.1111/j.1440-169X.2008.00993.X

Kalebic, N., Gilardi, C., Albert, M., Namba, T., Long, K. R., Kostic, M., et al. (2018). Human-specific ARHGAP11B induces hallmarks of neocortical expansion in developing ferret neocortex. Elife 7:e41241. doi: 10.1101/395830

Kamm, G. B., López-Leal, R., Lorenzo, J. R., and Franchini, L. F. (2013a). A fast-evolving human NPAS3 enhancer gained reporter expression in the developing forebrain of transgenic mice. Philos. Trans. R. Soc. Lond. B Biol. Sci. 368:20130019. doi: 10.1098/rstb.2013.0019

Kamm, G. B., Pisciottano, F., Kliger, R., and Franchini, L. F. (2013b). The developmental brain gene NPAS3 contains the largest number of accelerated regulatory sequences in the human genome. Mol. Biol. Evol. 30, 1088-1102. doi: $10.1093 / \mathrm{molbev} / \mathrm{mst} 023$

Katzman, S., Kern, A. D., Pollard, K. S., Salama, S. R., and Haussler, D. (2010). GC-biased evolution near human accelerated regions. PLoS Genet. 6:e1000960. doi: 10.1371/journal.pgen.1000960

Kelava, I., Reillo, I., Murayama, A. Y., Kalinka, A. T., Stenzel, D., Tomancak, P., et al. (2012). Abundant occurrence of basal radial glia in the subventricular zone of embryonic neocortex of a lissencephalic primate, the common marmoset Callithrix jacchus. Cereb. Cortex 22, 469-481. doi: 10.1093/cercor/bhr301

Kellis, M., Wold, B., Snyder, M. P., Bernstein, B. E., Kundaje, A., Marinov, G. K., et al. (2014). Defining functional DNA elements in the human genome. Proc. Natl. Acad. Sci. U.S.A. 111, 6131-6138. doi: 10.1073/pnas.1318948111

Kemp, T. S. (2005). The Origin and Evolution of Mammals. Oxford, NY: Oxford University Press.

Kemp, T. S. (2009). The endocranial cavity of a nonmammalian eucynodont, Chiniquodon theotenicus, and its implications for the origin of the mammalian brain. J. Vert. Paleontol. 29, 1188-1198. doi: 10.1671/039.029.0430

Kemp, T. S., and Parrington, F. R. (1979). The primitive cynodont Procynosuchus: functional anatomy of the skull and relationships. Philos. Trans. R. Soc. Lond. B Biol. Sci. 285, 73-122. doi: 10.1098/rstb.1979.0001

Kerjan, G., and Gleeson, J. G. (2007). Genetic mechanisms underlying abnormal neuronal migration in classical lissencephaly. Trends Genet. 23, 623-630. doi: 10.1016/j.tig.2007.09.003

Kermack, D. M., and Kermack, K. A. (1984). The Evolution of Mammalian Characters. Washington, DC: Kapitan Szabo Publishers. doi: 10.1007/978-1-4684-7817-4 
Kielan-Jaworowska, Z. (1986). "Brain evolution in Mesozoic mammals," in Vertebrates, Phylogeny, and Philosophy, eds K. M. Flanagan and J. A. Lillegraven (Laramie: University of Wyoming), 21-34.

Kielan-Jaworowska, Z., Cifelli, R. L., and Luo, Z.-X. (2005). Mammals Fromthe Age of Dinosaurs: Origins, Evolution, and Structure. New York, NY: Columbia University Press.

Komada, M., Saitsu, H., Kinboshi, M., Miura, T., Shiota, K., and Ishibashi, M. (2008). Hedgehog signaling is involved in development of the neocortex. Development 135, 2717-2727. doi: 10.1242/dev.015891

Korada, S., Zheng, W., Basilico, C., Schwartz, M. L., and Vaccarino, F. M. (2002). Fibroblast growth factor 2 is necessary for the growth of glutamate projection neurons in the anterior neocortex. J. Neurosci. 22, 863-875. doi: 10.1523/JNEUROSCI.22-03-00863.2002

Kostka, D., Hahn, M. W., and Pollard, K. S. (2010). Noncoding sequences near duplicated genes evolve rapidly. Genome Biol. Evol. 2, 518-533. doi: 10.1093/gbe/evq037

Kostka, D., Hubisz, M. J., Siepel, A., and Pollard, K. S. (2012). The role of GCbiased gene conversion in shaping the fastest evolving regions of the human genome. Mol. Biol. Evol. 29, 1047-1057. doi: 10.1093/molbev/msr279

Kou, Z., Wu, Q., Kou, X., Yin, C., Wang, H., Zuo, Z., et al. (2015). CRISPR/Cas9mediated genome engineering of the ferret. Cell Res. 25, 1372-1375. doi: $10.1038 /$ cr.2015.130

Kroenke, C. D., and Bayly, P. V. (2018). How forces fold the cerebral cortex. J. Neurosci. 38, 767-775. doi: 10.1523/JNEUROSCI.1105-17.2017

Krubitzer, L., Manger, P., Pettigrew, J., and Calford, M. (1995). Organization of somatosensory cortex in monotremes: in search of the prototypical plan. J. Comp. Neurol. 351, 261-306. doi: 10.1002/cne.903 510206

Laaß, M., and Kaestner, A. (2017). Evidence for convergent evolution of a neocortex-like structure in a late Permian therapsid. J. Morphol. 278, 1033-1057. doi: 10.1002/jmor.20712

Lai, C. S., Fisher, S. E., Hurst, J. A., Vargha-Khadem, F., and Monaco, A. P. (2001). A forkhead-domain gene is mutated in a severe speech and language disorder. Nature 413, 519-523. doi: 10.1038/35097076

Lai, H. C., Meredith, D. M., and Johnson, J. E. (2013). "bHLH Factors in Neurogenesis and Neuronal Subtype Specification," in Patterning and Cell Type Specification in the Developing CNS and PNS, eds J. Rubenstein and P. Rakic (Oxford, UK: Academic Press; Elsevier), 333-354.

Lancaster, M. A., and Knoblich, J. A. (2014). Generation of cerebral organoids from human pluripotent stem cells. Nat. Protoc. 9, 2329-2340. doi: $10.1038 /$ nprot.2014.158

Land, M. F., and Osorio, D. C. (2003). Colour vision: colouring the dark. Curr. Biol. 13, R83-R85. doi: 10.1016/S0960-9822(03)00031-9

Lander, E. S., Linton, L. M., Birren, B., Nusbaum, C., Zody, M. C., Baldwin, J., et al. (2001). Initial sequencing and analysis of the human genome. Nature 409, 860-921. doi: $10.1038 / 35057062$

Laurell, T., VanderMeer, J. E., Wenger, A. M., Grigelioniene, G., Nordenskjöld, A., Arner, M., et al. (2012). A novel 13 base pair insertion in the sonic hedgehog ZRS limb enhancer (ZRS/LMBR1) causes preaxial polydactyly with triphalangeal thumb. Hum. Mutat. 33, 1063-1066. doi: 10.1002/humu.22097

Letinic, K., Zoncu, R., and Rakic, P. (2002). Origin of GABAergic neurons in the human neocortex. Nature 417, 645-649. doi: 10.1038/nature00779

Lewitus, E., Kelava, I., and Huttner, W. B. (2013). Conical expansion of the outer subventricular zone and the role of neocortical folding in evolution and development. Front. Hum. Neurosci. 7:424. doi: 10.3389/fnhum.2013.00424

Lewitus, E., Kelava, I., Kalinka, A. T., Tomancak, P., and Huttner, W. B. (2014). An adaptive threshold in mammalian neocortical evolution. PLoS Biol. 12:e1002000. doi: 10.1371/journal.pbio. 1002000

Li, W., Cogswell, C. A., and LoTurco, J. J. (1998). Neuronal differentiation of precursors in the neocortical ventricular zone is triggered by BMP. J. Neurosci. 18, 8853-8862. doi: 10.1523/JNEUROSCI.18-21-08853.1998

Lim, L., Mi, D., Llorca, A., and Marín, O. (2018). Development and functional diversification of cortical interneurons. Neuron 100, 294-313. doi: 10.1016/j.neuron.2018.10.009

Llinares-Benadero, C., and Borrell, V. (2019). Deconstructing cortical folding: genetic, cellular and mechanical determinants. Nat. Rev. Neurosci. 20, 161-176. doi: 10.1038/s41583-018-0112-2
Logan, C. Y., and Nusse, R. (2004). The Wnt signaling pathway in development and disease. Annu. Rev. Cell Dev. Biol. 20, 781-810. doi: 10.1146/annurev.cellbio.20.010403.113126

Long, K. R., Newland, B., Florio, M., Kalebic, N., Langen, B., Kolterer, A., et al. (2018). Extracellular matrix components HAPLN1, lumican, and collagen I cause hyaluronic acid-dependent folding of the developing human neocortex. Neuron 99, 702-719.e6. doi: 10.1016/j.neuron.2018.07.013

Luis Villanueva-Cañas, J., Ruiz-Orera, J., Agea, M. I., Gallo, M., Andreu, D., and Albà, M. M. (2017). New genes and functional innovation in mammals. Genome Biol. Evol. 9, 1886-1900. doi: 10.1093/gbe/evx136

Macintyre, G., Alford, T., Xiong, L., Rouleau, G. A., Tibbo, P. G., and Cox, D. W. (2010). Association of NPAS3 exonic variation with schizophrenia. Schizophr. Res. 120, 143-149. doi: 10.1016/j.schres.2010. 04.002

Magen, D., Ofir, A., Berger, L., Goldsher, D., Eran, A., Katib, N., et al. (2015). Autosomal recessive lissencephaly with cerebellar hypoplasia is associated with a loss-of-function mutation in CDK5. Hum. Genet. 134, 305-314. doi: $10.1007 / \mathrm{s} 00439-014-1522-5$

Marino, L. (1998). A comparison of encephalization between odontocete cetaceans and anthropoid primates. Brain Behav. Evol. 51, 230-238. doi: $10.1159 / 000006540$

Marino, L. (2007). "Cetacean brain evolution," in Evolution of Nervous Systems, Vol. 3. ed J. Kaas (Oxford, UK), 261-266.

Marino, L., Connor, R. C., Fordyce, R. E., Herman, L. M., Hof, P. R., Lefebvre, L., et al. (2007). Cetaceans have complex brains for complex cognition. PLoS Biol. 5:e139. doi: 10.1371/journal.pbio.0050139

Martínez-Cerdeño, V., Cunningham, C. L., Camacho, J., Antczak, J. L., Prakash, A. N., Cziep, M. E., et al. (2012). Comparative analysis of the subventricular zone in rat, ferret and macaque: evidence for an outer subventricular zone in rodents. PLoS ONe 7:e30178. doi: 10.1371/journal.pone.00 30178

Martynoga, B., Morrison, H., Price, D. J., and Mason, J. O. (2005). Foxg1 is required for specification of ventral telencephalon and region-specific regulation of dorsal telencephalic precursor proliferation and apoptosis. Dev. Biol. 283, 113-127. doi: 10.1016/j.ydbio.2005.04.005

Marx, V. (2020). Reality check for organoids in neuroscience. Nat. Methods 17, 961-964. doi: 10.1038/s41592-020-0964-Z

Masuda, K., Toda, T., Shinmyo, Y., Ebisu, H., Hoshiba, Y., Wakimoto, M., et al. (2015). Pathophysiological analyses of cortical malformation using gyrencephalic mammals. Sci. Rep. 5:15370. doi: 10.1038/srep15370

Matsumoto, N., Shinmyo, Y., Ichikawa, Y., and Kawasaki, H. (2017). Gyrification of the cerebral cortex requires FGF signaling in the mammalian brain. Elife 6:e29285. doi: 10.7554/eLife.29285.022

Mayer, C., Jaglin, X. H., Cobbs, L. V., Bandler, R. C., Streicher, C., Cepko, C. L., et al. (2015). Clonally related forebrain interneurons disperse broadly across both functional areas and structural boundaries. Neuron 87, 989-998. doi: 10.1016/j.neuron.2015.07.011

McLean, C. Y., Reno, P. L., Pollen, A. A., Bassan, A. I., Capellini, T. D., Guenther, C., et al. (2011). Human-specific loss of regulatory DNA and the evolution of human-specific traits. Nature 471, 216-219. doi: 10.1038/nature09774

Medina, L. (2007). Do birds and reptiles possess homologues of mammalian visual, somatosensory, and motor cortices? Evol. Nervous Syst. 23, 1-12. doi: 10.1016/B0-12-370878-8/00132-4

Meyer, G. (2010). Building a human cortex: the evolutionary differentiation of Cajal-Retzius cells and the cortical hem. J. Anat. 217, 334-343. doi: 10.1111/j.1469-7580.2010.01266.x

Meyer, M., Kircher, M., Gansauge, M.-T., Li, H., Racimo, F., Mallick, S., et al. (2012). A high-coverage genome sequence from an archaic Denisovan individual. Science 338, 222-226. doi: 10.1126/science.1224344

Mi, D., Li, Z., Lim, L., Li, M., Moissidis, M., Yang, Y., et al. (2018). Early emergence of cortical interneuron diversity in the mouse embryo. Science 360, 81-85. doi: 10.1126/science.aar6821

Mihrshahi, R. (2006). The corpus callosum as an evolutionary innovation. J. Exp. Zool. B Mol. Dev. Evol. 306, 8-17. doi: 10.1002/jez.b.21067

Miller, D. J., Duka, T., Stimpson, C. D., Schapiro, S. J., Baze, W. B., McArthur, M. J., et al. (2012). Prolonged myelination in human neocortical evolution. Proc. Natl. Acad. Sci. U.S.A. 109, 16480-16485 doi: 10.1073/pnas.1117943109 
Miyazono, K., Kamiya, Y., and Morikawa, M. (2010). Bone morphogenetic protein receptors and signal transduction. J. Biochem. 147, 35-51. doi: $10.1093 / \mathrm{jb} / \mathrm{mvp} 148$

Molnár, Z. (2011). Evolution of cerebral cortical development. Brain Behav. Evol. 78, 94-107. doi: 10.1159/000327325

Montiel, J. F., and Aboitiz, F. (2015). Pallial patterning and the origin of the isocortex. Front. Neurosci. 9:377. doi: 10.3389/fnins.2015.00377

Montiel, J. F., Vasistha, N. A., Garcia-Moreno, F., and Molnár, Z. (2016). From sauropsids to mammals and back: new approaches to comparative cortical development. J. Comp. Neurol. 524, 630-645. doi: 10.1002/cne.23871

Morgane, P. J., Jacobs, M. S., and McFarland, W. L. (1980). The anatomy of the brain of the bottlenose dolphin (Tursiops truncatus). Surface configurations of the telencephalon of the bottlenose dolphin with comparative anatomical observations in four other cetacean species. Brain Res. Bull. 5, 1-107. doi: 10.1016/0361-9230(80)90272-5

Namba, T., Dóczi, J., Pinson, A., Xing, L., Kalebic, N., Wilsch-Bräuninger, M., et al. (2020). Human-specific ARHGAP11B Acts in mitochondria to expand neocortical progenitors by glutaminolysis. Neuron 105, 867-881.e9. doi: 10.1016/j.neuron.2019.11.027

Nanni, L., Ming, J. E., Bocian, M., Steinhaus, K., Bianchi, D. W., de DieSmulders, C., et al. (1999). The mutational spectrum of the sonic hedgehog gene in holoprosencephaly: $\mathrm{SHH}$ mutations cause a significant proportion of autosomal dominant holoprosencephaly. Hum. Mol. Genet. 8, 2479-2488. doi: 10.1093/hmg/8.13.2479

Nicholas, A. K., Khurshid, M., Désir, J., Carvalho, O. P., Cox, J. J., Thornton, G., et al. (2010). WDR62 is associated with the spindle pole and is mutated in human microcephaly. Nat. Genet. 42, 1010-1014. doi: 10.1038/ng.682

Nielsen, R., Bustamante, C., Clark, A. G., Glanowski, S., Sackton, T. B., Hubisz, M. J., et al. (2005). A scan for positively selected genes in the genomes of humans and chimpanzees. PLoS Biol. 3:e170. doi: 10.1371/journal.pbio.0030170

Niimura, Y., and Nei, M. (2005). Evolutionary dynamics of olfactory receptor genes in fishes and tetrapods. Proc. Natl. Acad. Sci. U.S.A. 102, 6039-6044. doi: 10.1073/pnas.0501922102

Nomura, T., Gotoh, H., and Ono, K. (2013a). Changes in the regulation of cortical neurogenesis contribute to encephalization during amniote brain evolution. Nat. Commun. 4:2206. doi: 10.1038/ncomms3206

Nomura, T., Hattori, M., and Osumi, N. (2009). Reelin, radial fibers and cortical evolution: insights from comparative analysis of the mammalian and avian telencephalon. Dev. Growth Differ. 51, 287-297. doi: 10.1111/j.1440-169X.2008.01073.x

Nomura, T., and Hirata, T. (2017). "The neocortical homologues in nonmammalian amniotes: bridging the hierarchical concepts of homology through comparative neurogenesis," in Evolution of the Nervous Systems, Vol. 2, ed J. H. Kaas (Oxford, UK; Elsevier), 195-204.

Nomura, T., Kawaguchi, M., and Ono, K. (2013b). Reptiles: a new model for brain evo-devo research. J. Exp. 320, 57-73. doi: 10.1002/jez.b.22484

Nomura, T., Takahashi, M., Hara, Y., and Osumi, N. (2008). Patterns of neurogenesis and amplitude of Reelin expression are essential for making a mammalian-type cortex. PLoS ONE 3:e1454. doi: 10.1371/journal.pone.0001454

Nord, A. S., Pattabiraman, K., Visel, A., and Rubenstein, J. L. R. (2015). Genomic perspectives of transcriptional regulation in forebrain development. Neuron 85 , 27-47. doi: 10.1016/j.neuron.2014.11.011

Northcutt, R. G., and Kaas, J. H. (1995). The emergence and evolution of mammalian neocortex. Trends Neurosci. 18, 373-379. doi: 10.1016/0166-2236(95)93932-N

Nowakowski, T. J., Pollen, A. A., Sandoval-Espinosa, C., and Kriegstein, A. R. (2016). Transformation of the radial glia scaffold demarcates two stages of human cerebral cortex development. Neuron 91, 1219-1227. doi: 10.1016/j.neuron.2016.09.005

O’Bleness, M., Searles, V. B., Varki, A., Gagneux, P., and Sikela, J. M. (2012). Evolution of genetic and genomic features unique to the human lineage. Nat. Rev. Genet. 13, 853-866. doi: 10.1038/nrg3336

O’Leary, M. A., Bloch, J. I., Flynn, J. J., Gaudin, T. J., Giallombardo, A., Giannini, N. P., et al. (2013). The placental mammal ancestor and the post-K-Pg radiation of placentals. Science 339, 662-667. doi: 10.1126/science.1229237
Ovcharenko, I., Stubbs, L., and Loots, G. G. (2004). Interpreting mammalian evolution using Fugu genome comparisons. Genomics 84, 890-895. doi: 10.1016/j.ygeno.2004.07.011

Pervaiz, N., and Abbasi, A. A. (2016). Molecular evolution of WDR62, a gene that regulates neocorticogenesis. Meta Gene 9, 1-9. doi: 10.1016/j.mgene.2016.02.005

Petanjek, Z., Berger, B., and Esclapez, M. (2009). Origins of cortical GABAergic neurons in the cynomolgus monkey. Cereb. Cortex 19, 249-262. doi: 10.1093/cercor/bhn078

Pickard, B. S., Christoforou, A., Thomson, P. A., Fawkes, A., Evans, K. L., Morris, S. W., et al. (2009). Interacting haplotypes at the NPAS3 locus alter risk of schizophrenia and bipolar disorder. Mol. Psychiatry 14, 874-884. doi: $10.1038 / \mathrm{mp} .2008 .24$

Pickard, B. S., Malloy, M. P., Porteous, D. J., Blackwood, D. H. R., and Muir, W. J. (2005). Disruption of a brain transcription factor, NPAS3, is associated with schizophrenia and learning disability. Am. J. Med. Genet. B Neuropsychiatr. Genet. 136B, 26-32. doi: 10.1002/ajmg.b.30204

Pilz, D. T., Matsumoto, N., Minnerath, S., Mills, P., Gleeson, J. G., Allen, K. M., et al. (1998). LIS1 and XLIS (DCX) mutations cause most classical lissencephaly, but different patterns of malformation. Hum. Mol. Genet. 7, 2029-2037. doi: 10.1093/hmg/7.13.2029

Pilz, G.-A., Shitamukai, A., Reillo, I., Pacary, E., Schwausch, J., Stahl, R., et al. (2013). Amplification of progenitors in the mammalian telencephalon includes a new radial glial cell type. Nat. Commun. 4:2125. doi: 10.1038/ncomms3125

Pla, R., Borrell, V., Flames, N., and Marín, O. (2006). Layer acquisition by cortical GABAergic interneurons is independent of Reelin signaling. J. Neurosci. 26, 6924-6934. doi: 10.1523/JNEUROSCI.0245-06.2006

Pollard, K. S., Salama, S. R., King, B., Kern, A. D., Dreszer, T., Katzman, S., et al. (2006a). Forces shaping the fastest evolving regions in the human genome. PLoS Genet. 2:e168. doi: 10.1371/journal.pgen.0020168

Pollard, K. S., Salama, S. R., Lambert, N., Lambot, M.-A., Coppens, S., Pedersen, J. S., et al. (2006b). An RNA gene expressed during cortical development evolved rapidly in humans. Nature 443, 167-172. doi: 10.1038/nature05113

Pollen, A. A., Bhaduri, A., Andrews, M. G., Nowakowski, T. J., Meyerson, O. S., Mostajo-Radji, M. A., et al. (2019). Establishing cerebral organoids as models of human-specific brain evolution. Cell 176, 743-756.e17. doi: 10.1016/j.cell.2019.01.017

Prabhakar, S., Noonan, J. P., Pääbo, S., and Rubin, E. M. (2006). Accelerated evolution of conserved noncoding sequences in humans. Science 314:786. doi: $10.1126 /$ science. 1130738

Preuss, (2007). "Primate brain evolution in phylogenetic context," in Evolution of Nervous Systems, Vol. 4, ed J. H. Kaas (Oxford, UK: Academic Press; Elsevier), $1-34$.

Preuss, T. M. (1995). Do rats have prefrontal cortex? The rose-woolsey-akert program reconsidered. J. Cogn. Neurosci. 7, 1-24. doi: 10.1162/jocn.1995.7.1.1

Preuss, T. M. (2010). Reinventing primate neuroscience for the twenty-first century. Prim. Neuroethol. 422-453. doi: 10.1093/acprof:oso/9780195326598.003.0022

Preuss, T. M. (2012). Human brain evolution: from gene discovery to phenotype discovery. Proc. Natl. Acad. Sci. U.S.A. 109(Suppl. 1), 10709-10716. doi: 10.1073/pnas.1201894109

Preuss, T. M., Qi, H., and Kaas, J. H. (1999). Distinctive compartmental organization of human primary visual cortex. Proc. Natl. Acad. Sci. U.S.A. 96, 11601-11606. doi: 10.1073/pnas.96.20.11601

Prüfer, K., Racimo, F., Patterson, N., Jay, F., Sankararaman, S., Sawyer, S., et al. (2014). The complete genome sequence of a Neanderthal from the Altai Mountains. Nature 505, 43-49. doi: 10.1038/nature12886

Ptak, S. E., Enard, W., Wiebe, V., Hellmann, I., Krause, J., Lachmann, M., et al. (2009). Linkage disequilibrium extends across putative selected sites in FOXP2. Mol. Biol. Evol. 26, 2181-2184. doi: 10.1093/molbev/msp143

Puelles, L., Ayad, A., Alonso, A., Sandoval, J. E., MartÍnez-de-laTorre, M., Medina, L., et al. (2016). Selective early expression of the orphan nuclear receptor $\mathrm{Nr} 4 \mathrm{a} 2$ identifies the claustrum homolog in the avian mesopallium: impact on sauropsidian/mammalian pallium comparisons. J. Comp. Neurol. 524, 665-703. doi: 10.1002/ cne. 23902 
Puelles, L., Sandoval, J. E., Ayad, A., del Corral, R., Alonso, A., Ferran, J. L., et al. (2017). The pallium in reptiles and birds in the light of the updated tetrapartite pallium model. Evol. Nervous Syst. 1, 519-555. doi: 10.1016/B978-0-12-804042-3.00014-2

Qian, X., Song, H., and Ming, G.-L. (2019). Brain organoids: advances, applications and challenges. Development 146:dev166074. doi: 10.1242/dev.166074

Quiroga, J. C. (1980). The brain of the mammal-like reptile Probainognathus jenseni (Therapsida, Cynodontia). A correlative paleo-neoneurological approach to the neocortex at the reptile-mammal transition. J. Hirnforsch. $21,299-336$

Raballo, R., Rhee, J., Lyn-Cook, R., Leckman, J. F., Schwartz, M. L., and Vaccarino, F. M. (2000). Basic fibroblast growth factor (Fgf2) is necessary for cell proliferation and neurogenesis in the developing cerebral cortex. J. Neurosci. 20, 5012-5023. doi: 10.1523/JNEUROSCI.20-13-05012.2000

Racimo, F., Kuhlwilm, M., and Slatkin, M. (2014). A test for ancient selective sweeps and an application to candidate sites in modern humans. Mol. Biol. Evol. 31, 3344-3358. doi: 10.1093/molbev/msu255

Rakic, P. (2009). Evolution of the neocortex: a perspective from developmental biology. Nat. Rev. Neurosci. 10, 724-735. doi: 10.1038/nrn2719

Rash, B. G., Tomasi, S., Lim, H. D., Suh, C. Y., and Vaccarino, F. M. (2013). Cortical gyrification induced by fibroblast growth factor 2 in the mouse brain. J. Neurosci. 33, 10802-10814. doi: 10.1523/JNEUROSCI.3621-12.2013

Ratnakumar, A., Mousset, S., Glémin, S., Berglund, J., Galtier, N., Duret, L., et al. (2010). Detecting positive selection within genomes: the problem of biased gene conversion. Philos. Trans. R. Soc. Lond. B Biol. Sci. 365, 2571-2580. doi: 10.1098/rstb.2010.0007

Reillo, I., and Borrell, V. (2012). Germinal zones in the developing cerebral cortex of ferret: ontogeny, cell cycle kinetics, and diversity of progenitors. Cereb. Cortex 22, 2039-2054. doi: 10.1093/cercor/bhr284

Reillo, I., de Juan Romero, C., García-Cabezas, M. Á., and Borrell, V. (2011). A role for intermediate radial glia in the tangential expansion of the mammalian cerebral cortex. Cereb. Cortex 21, 1674-1694. doi: 10.1093/cercor/bhq238

Reiner, A., Perkel, D. J., Bruce, L. L., Butler, A. B., Csillag, A., Kuenzel, W., et al. (2004). Revised nomenclature for avian telencephalon and some related brainstem nuclei. J. Comp. Neurol. 473, 377-414. doi: 10.1002/cne.20118

Rhesus Macaque Genome Sequencing and Analysis Consortium, Gibbs, R. A., Rogers, J., Katze, M. G., Bumgarner, R., Weinstock, G. M., et al. (2007). Evolutionary and biomedical insights from the rhesus macaque genome. Science 316, 222-234. doi: 10.1126/science.1139247

Richman, D. P., Stewart, R. M., Hutchinson, J. W., and Caviness, V. S. Jr. (1975). Mechanical model of brain convolutional development. Science 189, 18-21. doi: $10.1126 /$ science. 1135626

Ridgway, S., Carder, D., Jeffries, M., and Todd, M. (2012). Spontaneous human speech mimicry by a cetacean. Curr. Biol. 22, R860-R861. doi: 10.1016/j.cub.2012.08.044

Rilling, J. K., Glasser, M. F., Preuss, T. M., Ma, X., Zhao, T., Hu, X., et al. (2008). The evolution of the arcuate fasciculus revealed with comparative DTI. Nat. Neurosci. 11, 426-428. doi: 10.1038/nn2072

Roelink, H., Augsburger, A., Heemskerk, J., Korzh, V., Norlin, S., Ruiz i Altaba, A., et al. (1994). Floor plate and motor neuron induction by vhh-1, a vertebrate homolog of hedgehog expressed by the notochord. Cell 76, 761-775. doi: 10.1016/0092-8674(94)90514-2

Rohatgi, R., Milenkovic, L., and Scott, M. P. (2007). Patched1 regulates hedgehog signaling at the primary cilium. Science 317, 372-376. doi: $10.1126 /$ science. 1139740

Roth, G., and Dicke, U. (2005). Evolution of the brain and intelligence. Trends Cogn. Sci. 9, 250-257. doi: 10.1016/j.tics.2005.03.005

Rowe, T. B. (2017). The Emergence of Mammals. Evol. Nervous Syst. 2, 1-52. doi: 10.1016/B978-0-12-804042-3.00029-4

Rowe, T. B., Macrini, T. E., and Luo, Z.-X. (2011). Fossil evidence on origin of the mammalian brain. Science 332, 955-957. doi: 10.1126/science.1203117

Santangelo, A. M., de Souza, F. S. J., Franchini, L. F., Bumaschny, V. F., Low, M. J., and Rubinstein, M. (2007). Ancient exaptation of a CORE-SINE retroposon into a highly conserved mammalian neuronal enhancer of the proopiomelanocortin gene. PLoS Genet. 3, 1813-1826. doi: 10.1371/journal.pgen.0030166

Sasaki, H., Nishizaki, Y., Hui, C., Nakafuku, M., and Kondoh, H. (1999). Regulation of Gli2 and Gli3 activities by an amino-terminal repression domain: implication of Gli2 and Gli3 as primary mediators of Shh signaling. Development 126, 3915-3924.

Sasaki, T., Nishihara, H., Hirakawa, M., Fujimura, K., Tanaka, M., Kokubo, N., et al. (2008). Possible involvement of SINEs in mammalian-specific brain formation. Proc. Natl. Acad. Sci. U.S.A. 105, 4220-4225. doi: 10.1073/pnas.0709398105

Sayigh, L. S. (2014). "Cetacean acoustic communication," in Biocommunication of Animals, ed. G. Witzany (Dordrecht: Springer Netherlands), 275-297.

Scharff, C., and Petri, J. (2011). Evo-devo, deep homology and FoxP2: implications for the evolution of speech and language. Philos. Trans. R. Soc. Lond. B Biol. Sci. 366, 2124-2140. doi: 10.1098/rstb.2011.0001

Schroeter, E. H., Kisslinger, J. A., and Kopan, R. (1998). Notch-1 signalling requires ligand-induced proteolytic release of intracellular domain. Nature 393, 382-386. doi: 10.1038/30756

Schwartz, S., Zhang, Z., Frazer, K. A., Smit, A., Riemer, C., Bouck, J., et al. (2000). PipMaker-a web server for aligning two genomic DNA sequences. Genome Res. 10, 577-586. doi: 10.1101/gr.10.4.577

Semendeferi, K., Armstrong, E., Schleicher, A., Zilles, K., and Van Hoesen, G. W. (2001). Prefrontal cortex in humans and apes: a comparative study of area 10. Am. J. Phys. Anthropol. 114, 224-241. doi: 10.1002/1096-8644(200103)114:3<224::AID-AJPA1022>3.0.CO;2-I

Shakèd, M., Weissmüller, K., Svoboda, H., Hortschansky, P., Nishino, N., Wölfl, S., et al. (2008). Histone deacetylases control neurogenesis in embryonic brain by inhibition of BMP2/4 signaling. PLOS ONE 3:e2668. doi: 10.1371/journal.pone.0002668

Sherwood, C. C., Subiaul, F., and Zawidzki, T. W. (2008). A natural history of the human mind: tracing evolutionary changes in brain and cognition. J. Anat. 212, 426-454. doi: 10.1111/j.1469-7580.2008.00868.x

Shi, Y., and Massagué, J. (2003). Mechanisms of TGF-beta signaling from cell membrane to the nucleus. Cell 113, 685-700. doi: 10.1016/S0092-8674(03)00432-X

Shinmyo, Y., Terashita, Y., Dinh Duong, T. A., Horiike, T., Kawasumi, M., Hosomichi, K., et al. (2017). Folding of the cerebral cortex requires Cdk5 in upper-layer neurons in gyrencephalic mammals. Cell Rep. 20, 2131-2143. doi: 10.1016/j.celrep.2017.08.024

Shou, Y., Liang, F., Xu, S., and Li, X. (2020). The application of brain organoids: from neuronal development to neurological diseases. Front. Cell Dev. Biol. 8:1092. doi: 10.3389/fcell.2020.579659

Siepel, A. (2005). Evolutionarily conserved elements in vertebrate, insect, worm, and yeast genomes. Genome Res. 15, 1034-1050. doi: 10.1101/gr.3715005

Sikela, J. M. (2006). The jewels of our genome: the search for the genomic changes underlying the evolutionarily unique capacities of the human brain. PLoS Genet. 2:e80. doi: 10.1371/journal.pgen.0020080

Silver, D. L. (2016). Genomic divergence and brain evolution: how regulatory DNA influences development of the cerebral cortex. Bioessays 38, 162-171. doi: $10.1002 /$ bies. 201500108

Smaers, J. B. (2013). How humans stand out in frontal lobe scaling. Proc. Natl. Acad. Sci. U.S.A. 110:E3682. doi: 10.1073/pnas.1308850110

Smaers, J. B., Gómez-Robles, A., Parks, A. N., and Sherwood, C. C. (2017). Exceptional evolutionary expansion of prefrontal cortex in great apes and humans. Curr. Biol. 27:1549. doi: 10.1016/j.cub.2017.05.015

Smart, I. H. M., Dehay, C., Giroud, P., Berland, M., and Kennedy, H. (2002). Unique morphological features of the proliferative zones and postmitotic compartments of the neural epithelium giving rise to striate and extrastriate cortex in the monkey. Cereb. Cortex 12, 37-53. doi: 10.1093/cercor/12.1.37

Sousa, A. M. M., Meyer, K. A., Santpere, G., Gulden, F. O., and Sestan, N. (2017). Evolution of the human nervous system function, structure, and development. Cell 170, 226-247. doi: 10.1016/j.cell.2017.06.036

Stahl, R., Walcher, T., De Juan Romero, C., Pilz, G. A., Cappello, S., Irmler, M., et al. (2013). Trnp1 regulates expansion and folding of the mammalian cerebral cortex by control of radial glial fate. Cell 153, 535-549. doi: $10.1016 /$ j.cell.2013.03.027

Stanco, A., Pla, R., Vogt, D., Chen, Y., Mandal, S., Walker, J., et al. (2014). NPAS1 represses the generation of specific subtypes of cortical interneurons. Neuron 84, 940-953. doi: 10.1016/j.neuron.2014. 10.040

Stifani, S., Blaumueller, C. M., Redhead, N. J., Hill, R. E., and Artavanis-Tsakonas, S. (1992). Human homologs of a Drosophila Enhancer of split gene product define a novel family of nuclear proteins. Nat. Genet. 2:343. doi: 10.1038/ng1092-119 
Storm, E. E., Garel, S., Borello, U., Hebert, J. M., Martinez, S., McConnell, S. K., et al. (2006). Dose-dependent functions of Fgf8 in regulating telencephalic patterning centers. Development 133, 1831-1844. doi: 10.1242/dev.02324

Striedter, G. F. (2005). Principles of Brain Evolution. Sunderland, MA: Sinauer Associates.

Striedter, G. F., Srinivasan, S., and Monuki, E. S. (2015). Cortical folding: when, where, how, and why? Annu. Rev. Neurosci. 38, 291-307. doi: 10.1146/annurev-neuro-071714-034128

Struhl, G., and Adachi, A. (1998). Nuclear access and action of notch in vivo. Cell 93, 649-660. doi: 10.1016/S0092-8674(00)81193-9

Sumiyama, K., and Saitou, N. (2011). Loss-of-function mutation in a repressor module of human-specifically activated enhancer HACNS1. Mol. Biol. Evol. 28, 3005-3007. doi: 10.1093/molbev/msr231

Suzuki, I. K., Gacquer, D., Van Heurck, R., Kumar, D., Wojno, M., Bilheu, A., et al. (2018). Human-specific NOTCH2NL genes expand cortical neurogenesis through delta/notch regulation. Cell 173, 1370-1384.e16. doi: 10.1016/j.cell.2018.03.067

Swenson, R. S. (2006). Review of Clinical and Functional Neuroscience. Educational Review Manual in Neurology. Dartmouth Medical School Available online at: https://www.e-booksdirectory.com/details.php?ebook $=7494$

Taglialatela, J. P., Russell, J. L., Schaeffer, J. A., and Hopkins, W. D. (2008). Communicative signaling activates "Brocas" homolog in chimpanzees. Curr. Biol. 18, 343-348. doi: 10.1016/j.cub.2008.01.049

Tanaka, D. H., and Nakajima, K. (2012). GABAergic interneuron migration and the evolution of the neocortex. Dev. Growth Differ. 54, 366-372. doi: 10.1111/j.1440-169X.2012.01351.x

Thewissen, J. G., Williams, E. M., Roe, L. J., and Hussain, S. T. (2001). Skeletons of terrestrial cetaceans and the relationship of whales to artiodactyls. Nature 413, 277-281. doi: 10.1038/35095005

Tissir, F., De Rouvroit, C. L., Sire, J.-Y., Meyer, G., and Goffinet, A. M. (2003). Reelin expression during embryonic brain development in Crocodylus niloticus. J. Comp. Neurol. 457, 250-262. doi: 10.1002/cne.10573

Vallender, E. J., Mekel-Bobrov, N., and Lahn, B. T. (2008). Genetic basis of human brain evolution. Trends Neurosci. 31, 637-644. doi: 10.1016/j.tins.2008. 08.010

Van Essen, D. C. (1997). A tension-based theory of morphogenesis and compact wiring in the central nervous system. Nature 385, 313-318. doi: $10.1038 / 385313 \mathrm{a} 0$

Varki, A., and Altheide, T. K. (2005). Comparing the human and chimpanzee genomes: searching for needles in a haystack. Genome Res. 15, 1746-1758. doi: 10.1101/gr.3737405

Walls, G. L. (1942). The Vertebrate Eye and Its Adaptive Radiation. Cranbrook Institute of Science.

Wang, L., Hou, S., and Han, Y.-G. (2016). Hedgehog signaling promotes basal progenitor expansion and the growth and folding of the neocortex. Nat. Neurosci. 19, 888-896. doi: 10.1038/nn.4307

Wang, X., Tsai, J.-W., LaMonica, B., and Kriegstein, A. R. (2011). A new subtype of progenitor cell in the mouse embryonic neocortex. Nat. Neurosci. 14, 555-561. doi: 10.1038/nn.2807

Wei, Y., de Lange, S. C., Scholtens, L. H., Watanabe, K., Ardesch, D. J., Jansen, P. R., et al. (2019). Genetic mapping and evolutionary analysis of human-expanded cognitive networks. Nat. Commun. 10:4839. doi: 10.1038/s41467-019-12764-8

Welker,W. (1990). "Why does the cortex fissure and fold: a review of determinants of gyri and sulci," in Comparative Structure and Evolution of Cerebral Cortex, eds A. Peters and E. G. Jones (New York, NY: Plenum Press), 3-136. doi: 10.1007/978-1-4615-3824-0

Won, H., Huang, J., Opland, C. K., Hartl, C. L., and Geschwind, D. H. (2019). Human evolved regulatory elements modulate genes involved in cortical expansion and neurodevelopmental disease susceptibility. Nat. Commun. 10:2396. doi: 10.1038/s41467-019-10248-3

Wu, C. W., Bichot, N. P., and Kaas, J. H. (2000). Converging evidence from microstimulation, architecture, and connections for multiple motor areas in the frontal and cingulate cortex of prosimian primates. J. Comp. Neurol. 423, 140-177. doi: 10.1002/1096-9861(20000717)423:1<140::aid-cne12>3.0.co;2-3
Xu, G., Knutsen, A. K., Dikranian, K., Kroenke, C. D., Bayly, P. V., and Taber, L. A. (2010). Axons pull on the brain, but tension does not drive cortical folding. J. Biomech. Eng. 132:071013. doi: 10.1115/1.4001683

Xu, Q., Guo, L., Moore, H., Waclaw, R. R., Campbell, K., and Anderson, S. A. (2010). Sonic hedgehog signaling confers ventral telencephalic progenitors with distinct cortical interneuron fates. Neuron 65, 328-340. doi: 10.1016/j.neuron.2010.01.004

Yabut, O., Renfro, A., Niu, S., Swann, J. W., Marín, O., and D’Arcangelo, G. (2007). Abnormal laminar position and dendrite development of interneurons in the reeler forebrain. Brain Res. 1140, 75-83. doi: 10.1016/j.brainres.2005.09.070

Yabut, O. R., Ng, H.-X., Yoon, K., Gomez, H. G., Arela, J. C., and Pleasure, S. J. (2020). Combined modulation of SHH and FGF signaling is crucial for maintenance of the neocortical progenitor specification program. J. Neurosci. 40, 6872-6887. doi: 10.1523/JNEUROSCI.2888-19.2020

Yeh, M. L., Gonda, Y., Mommersteeg, M. T. M., Barber, M., Ypsilanti, A. R., Hanashima, C., et al. (2014). Robol modulates proliferation and neurogenesis in the developing neocortex. J. Neurosci. 34, 5717-5731. doi: 10.1523/JNEUROSCI.4256-13.2014

Ypsilanti, A. R., and Rubenstein, J. L. R. (2016). Transcriptional and epigenetic mechanisms of early cortical development: an examination of how Pax6 coordinates cortical development. J. Comp. Neurol. 524, 609-629. doi: $10.1002 /$ cne.23866

Yu, T. W., Mochida, G. H., Tischfield, D. J., Sgaier, S. K., Flores-Sarnat, L., Sergi, C. M., et al. (2010). Mutations in WDR62, encoding a centrosomeassociated protein, cause microcephaly with simplified gyri and abnormal cortical architecture. Nat. Genet. 42, 1015-1020. doi: 10.1038/ng.683

Yu, X., and Zecevic, N. (2011). Dorsal radial glial cells have the potential to generate cortical interneurons in human but not in mouse brain. J. Neurosci. (2011) 31, 2413-2420. doi: 10.1523/JNEUROSCI.5249-10.2011

Yu, X.-J., Zheng, H.-K., Wang, J., Wang, W., and Su, B. (2006). Detecting lineage-specific adaptive evolution of brain-expressed genes in human using rhesus macaque as outgroup. Genomics 88, 745-751. doi: 10.1016/j.ygeno.2006. 05.008

Yunis, J., and Prakash, O. (1982). The origin of man: a chromosomal pictorial legacy The origin of man: a chromosomal pictorial legacy. Science 215, 1525-1530. doi: 10.1126/science.7063861

Zhang, J., Webb, D. M., and Podlaha, O. (2002). Accelerated protein evolution and origins of human-specific features: Foxp2 as an example. Genetics 162, $1825-1835$.

Zhang, R., Engler, A., and Taylor, V. (2018). Notch: an interactive player in neurogenesis and disease. Cell Tissue Res. 371, 73-89. doi: 10.1007/s00441-017-2641-9

Zheng, Q., Cai, X., Tan, M. H., Schaffert, S., Arnold, C. P., Gong, X., et al. (2014). Precise gene deletion and replacement using the CRISPR/Cas9 system in human cells. Biotechniques 57, 115-124. doi: 10.2144/0001 14196

Zheng, W., Geng, A.-Q., Li, P.-F., Wang, Y., and Yuan, X.-B. (2012). Robo4 regulates the radial migration of newborn neurons in developing neocortex. Cereb. Cortex 22, 2587-2601. doi: 10.1093/cercor/bhr330

Zilles, K., Palomero-Gallagher, N., and Amunts, K. (2013). Development of cortical folding during evolution and ontogeny. Trends Neurosci. 36, 275-284. doi: 10.1016/j.tins.2013. 01.006

Conflict of Interest: The author declares that the research was conducted in the absence of any commercial or financial relationships that could be construed as a potential conflict of interest.

Copyright (c) 2021 Franchini. This is an open-access article distributed under the terms of the Creative Commons Attribution License (CC BY). The use, distribution or reproduction in other forums is permitted, provided the original author(s) and the copyright owner(s) are credited and that the original publication in this journal is cited, in accordance with accepted academic practice. No use, distribution or reproduction is permitted which does not comply with these terms. 